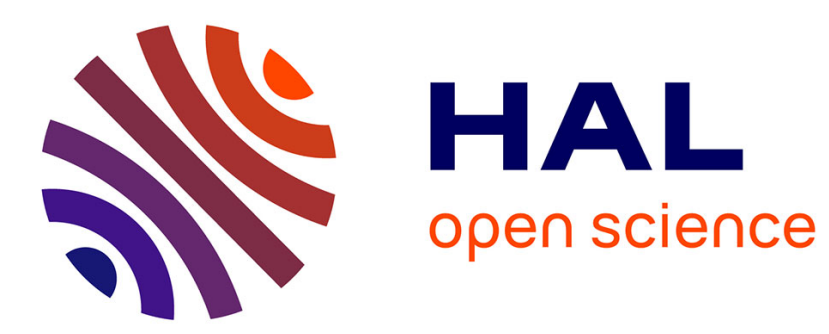

\title{
Design, Synthesis, and Evaluation of Enhanced DNA Binding New Lipopolythioureas
}

Jeanne Leblond, Nathalie Mignet, Lucie Leseurre, Celine Largeau, Michel Bessodes, Daniel Scherman, Jean Herscovici

\section{To cite this version:}

Jeanne Leblond, Nathalie Mignet, Lucie Leseurre, Celine Largeau, Michel Bessodes, et al.. Design, Synthesis, and Evaluation of Enhanced DNA Binding New Lipopolythioureas. Bioconjugate Chemistry, inPress, 10.1021/bc060110g . hal-02512562

\section{HAL Id: hal-02512562 \\ https://hal.science/hal-02512562}

Submitted on 19 Mar 2020

HAL is a multi-disciplinary open access archive for the deposit and dissemination of scientific research documents, whether they are published or not. The documents may come from teaching and research institutions in France or abroad, or from public or private research centers.
L'archive ouverte pluridisciplinaire HAL, est destinée au dépôt et à la diffusion de documents scientifiques de niveau recherche, publiés ou non, émanant des établissements d'enseignement et de recherche français ou étrangers, des laboratoires publics ou privés. 


\title{
Design, Synthesis, and Evaluation of Enhanced DNA Binding New Lipopolythioureas
}

\author{
Jeanne Leblond, Nathalie Mignet, Lucie Leseurre, Céline Largeau, Michel Bessodes, Daniel Scherman, and \\ Jean Herscovici* \\ Inserm, U640, Paris, F-75006 France, CNRS, UMR8151, Paris, F-75006 France, Ecole Nationale Supérieure de Chimie de Paris, \\ Paris, F-75005, Unité de Pharmacologie Chimique et Génétique, France, Université Paris Descartes, Faculté de Pharmacie Paris, \\ F-75270 France, and Institut de Chimie Moléculaire de Paris Centre, CNRS FR 2769, F-75005. Received April 27, 2006; \\ Revised Manuscript Received July 6, 2006
}

\begin{abstract}
Nonviral gene delivery is limited to a large extent by the cationic nature of most of the chemical vector. We have shown that lipopolythioureas interact with DNA. However, lipopolythioureas were not very efficient at transfecting cells, probably due to reduced interaction between the noncationic synthetic lipid and the cell membrane. Here, we report that liposomes made from a new thiourea lipid, DPPC, and a lipid bearing an RGD ligand allowed very efficient entry of the lipopolythioureas into integrin $\alpha_{\mathrm{v}} \beta_{3}$ expressing cells. In addition, we show that a stable interaction between DNA and lipopolythiourea could be obtain with two thiourea groups. Moreover, the addition of a hydrophilic terminus improves the formulation of these new DNA binding agents.
\end{abstract}

\section{INTRODUCTION}

Gene therapy considers the use of nucleic acid as a drug to treat or cure acquired or innate diseases. In most cases, the genetic material must be packed in a delivery system to be protected from nucleases and to cross physiological barriers and/ or cell membranes (1). During the past years, efforts have been undertaken to develop physical $(2)$, viral $(3,4)$, or synthetic DNA delivery processes $(5,6)$. Because of the polyanionic nature of DNA and the overall negative charge of cell membranes, nonviral vectors are mostly cationic. They have been proven to efficiently transfect cells in culture. However, most of them are ineffective for in vivo DNA delivery, due to interaction with serum, opsonins, or other physiological components (7). To improve synthetic vector efficiency, several attempts have been made to mask (8) or suppress cationic charges $(9,10)$.

Thiourea derivatives have been intensively investigated in the area of molecular recognition due to their strong hydrogenbonding activity (11). Moreover, bis-thiourea moieties selectively bind to dihydrogenphosphate via multitopic hydrogen bonding, giving stronger complexes with $\mathrm{H}_{2} \mathrm{PO}_{4}{ }^{-}$than any synthetic neutral receptor known so far (12).

On the basis of these data, which suggested that stable lipoplexes could be made from the interaction between thiourea and nucleic acid, we reported that $N$-(2-\{3-[2-(2-\{3-[2-(3-methylthioureido)ethyl]thioureido\}ethylamino)ethyl]thioureido $\}$ ethyl)- $N^{\prime}, N^{\prime}$-ditetradecylsuccinamide (DTTU, Figure 1) formulated with DPPC were able to interact with DNA and formed nanometric particles (13). This new lipopolythiourea lipid (LPT) was composed of a hydrophobic anchor connected to a linear trithiourea. Lipopolythiourea lipoplexes made from DTTU exhibited a longer circulation time in the blood than cationic lipid RPR209120 (14) taken as a reference compound. However, this particular lipopolythiourea was difficult to formulate as liposome because of its highly hydrophobic nature and presented very poor transfecting properties. These primary results clearly indicated that the LPT physicochemical properties and perhaps their interaction with cell membranes have to be improved.

\footnotetext{
* Email: jean-herscovici@enscp.fr.
}

A recent study using density functional theory (DFT) calculation (15) predicts that DTTU binds to DNA by six hydrogen bonds with a major contribution of thioureas II and III that form four of the six bonds (Figure 1). This interaction induces a conformational change with the three thiourea groups, normally in trans from one another in the bare molecule, which moves into the cis position. From these predictions, it could be expected that a headgroup containing two thioureas will lead to a stable complex with nucleic acid. On the other hand, it has been reported that a $\mathrm{T}$-shaped branched structure improved the transfecting properties of cationic polyamine (16). Moreover, such a structure will probably avoid the constraints due to the cis conformation of DTTU.

So, we designed new noncationic lipids with a T-shaped bisthiourea headgroup. We introduced also hydroxyl and diol termini, which have been proven to have a positive effect on transfection efficiency (17). Finally, we chose two different linkers composed of a benzyl group or a 3-motives-PEG to connect the hydrophobic anchor to the headgroup. These new lipopolythioureas (LPT) have been synthesized and evaluated in terms of DNA compaction and transfection efficiency. As a final point, we investigated RGD-mediated internalization of endothelial cells expressing integrin $\alpha_{\mathrm{v}} \beta_{3}$.

\section{MATERIALS AND METHODS}

All solvents were purchased from Carlo Erba-SDS (Peypin France). Dichloromethane was distilled from $\mathrm{P}_{2} \mathrm{O}_{5}$. DMF was dried over $3 \AA$ molecular sieves and pyridine over $\mathrm{KOH}$. All chemicals were purchased from Sigma-Aldrich-Fluka or Lancaster. Tosyl chloride (petroleum ether) and cholesteryl chloroformate (acetone) were recrystallized, and diglycolic anhydride was dehydrated $\left(\mathrm{P}_{2} \mathrm{O}_{5}\right)$ prior to use. Other solvents and products were used without further purification. Reactions were monitored by thin-layer chromatography using Merck precoated 60 F254 silica gel plates. Column chromatography was performed over SDS (Peypin France) 35-70 m silicagel according to the method of Still, Khan, and Mitra (18) or using small-column flash chromatography (SFC) according to the following procedure. A plastic syringe was filled with silicagel (product/silicagel $1 / 5)$ and connected to vacuum $(12 \mathrm{mmHg})$. The column was 


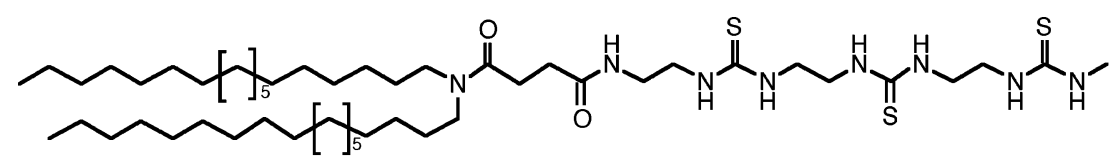

Figure 1. Structures of the linear trithiourea DTTU.

equilibrated with heptane, then the sample dissolved in a minimum of dichloromethane was added to the top. The column was eluted by ten fractions of a heptane/ethyl acetate mixture. The volume was equal to the silicagel volume. For each fraction, the amount of ethyl acetate was increased (10\% (v/v) to $100 \%$ ethyl acetate in heptane). Inverse-phase solid-phase extraction (SPE) was performed on a Supelco Superclean C8 cartridge using water/acetonitrile/methanol mixture. ${ }^{1} \mathrm{H}$ and ${ }^{13} \mathrm{C}$ NMR spectra were recorded on a Bruker Advance DRX-300 spectrometer at $300.13 \mathrm{MHz}$ for ${ }^{1} \mathrm{H}$ and $75.47 \mathrm{MHz}$ for ${ }^{13} \mathrm{C}$. NMR spectra were processed using XwinNmr (Bruker) or SwaN-MR (19). Mass spectra were carried out on a Shimazu 2010A LC-MS on ESI mode. High-resolution mass spectra and elemental analysis were carried out by the "Service Central de Micro-analyse du CNRS" Vernaison France. Dipalmytoylphosphatidylcholine (DPPC) and phosphatidylethanolamine lissamine rhodamine were purchased from Aventi Polar Lipids (Alabaster, Alabama).

Synthesis of Lipopolythioureas. 2,3-Dihydroxy-1,4-di-paratoluenesulfonyloxy butane (2). A dichloromethane solution (60 $\mathrm{mL}$ ) of tosyl chloride (15.6 g, $82 \mathrm{mmol})$ was added dropwise for $5 \mathrm{~h}$ to a cooled $\left(-20{ }^{\circ} \mathrm{C}\right)$ pyridine solution $(16.6 \mathrm{~mL}, 0.21$ mole) of D,L-threitol $(5.0 \mathrm{~g}, 41 \mathrm{mmol})$. The reaction mixture was stirred overnight at $0{ }^{\circ} \mathrm{C}$, then the solvent was evaporated. $1 \mathrm{~N} \mathrm{HCl}(100 \mathrm{~mL})$ was added to the residual oil that was extracted six times with dichloromethane. The combined organic layers were washed with brine, dried $\left(\mathrm{MgSO}_{4}\right)$, and then evaporated under reduced pressure. The residual oil was purified by chromatography (heptane/ethyl acetate 6:4) to yield $9.1 \mathrm{~g}$ of 2 as a white solid $(52 \%)$. mp $83{ }^{\circ} \mathrm{C} .{ }^{1} \mathrm{H} \mathrm{NMR}\left(\mathrm{CDCl}_{3}\right) \delta$ (ppm) $2.44\left(\mathrm{~s}, 6 \mathrm{H}, \mathrm{CH}_{3}\right), 2.95(\mathrm{~m}, 2 \mathrm{H}, \mathrm{OH}), 3.88(\mathrm{~m}, 2 \mathrm{H}$, $\mathrm{CHOH}), 4.05\left(\mathrm{~d}, 4 \mathrm{H}, J=5 \mathrm{~Hz}, \mathrm{CH}_{2} \mathrm{O}\right), 7.35(\mathrm{~d}, 4 \mathrm{H}, J=8.1$ $\left.\mathrm{Hz}, \mathrm{H}_{\text {arom }}\right), 7.88\left(\mathrm{~d}, 4 \mathrm{H}, J=8.1 \mathrm{~Hz}, \mathrm{H}_{\text {arom }}\right) .{ }^{13} \mathrm{C} \mathrm{NMR}\left(\mathrm{CDCl}_{3}\right)$ $\delta(\mathrm{ppm}) 21.80\left(\mathrm{~s}, \mathrm{CH}_{3}\right), 68.62(\mathrm{~s}, \mathrm{CHOH}), 71.05\left(\mathrm{~s}, \mathrm{CH}_{2} \mathrm{O}\right)$, 128.96 (s, $\left.\mathrm{CH}_{\text {arom }}\right), 130.21\left(\mathrm{CH}_{\text {arom }}\right), 132.68$ (s, $\left.\mathrm{C}_{\text {arom }}\right), 145.81$ (s, $\mathrm{C}_{\text {arom }}$ ). MS (ESI, $\left.m / z\right) 431(\mathrm{M}+\mathrm{H})^{+}$, HPLC purity $96 \%$ by ELSD. Anal. Calcd for $\mathrm{C}_{18} \mathrm{H}_{22} \mathrm{O}_{8} \mathrm{~S}_{2} \mathrm{C}, 50.22 ; \mathrm{H}, 5.15 ; \mathrm{N}, 14.90$. Found: C, 50.21; H, 5.35; N, 14.64.

4-[4,5-Bis-(toluene-4-sulfonyloxymethyl)-1,3-dioxolan-2-yl]benzoic Acid Methyl Ester (4). A solution of diol 2 (1.07 g, 2.5 mmol), para-toluene sulfonic acid monohydrate (48 mg, 0.25 $\mathrm{mmol})$, and 4-dimethoxymethylbenzoic acid methyl ester 3 (0.58 $\mathrm{g}, 2.75 \mathrm{mmol})$ in dry benzene $(30 \mathrm{~mL})$ was heated under reflux with a Dean-Stark trap during $5 \mathrm{~h}$. Then, pyridine was added $(0.5 \mathrm{~mL})$, and the reaction mixture was concentrated under reduced pressure. The resulting solid was purified by flash chromatography (heptane/ethyl acetate $/ \mathrm{CH}_{2} \mathrm{Cl}_{2} \quad 4: 1: 1$, then 4:4:1) to afford $1.1 \mathrm{~g}$ of dioxolane 4 as a white solid (75\%). $\mathrm{mp} 130^{\circ} \mathrm{C} .{ }^{1} \mathrm{H} \mathrm{NMR}\left(\mathrm{CDCl}_{3}\right) \delta(\mathrm{ppm}) 2.45\left(\mathrm{~s}, 6 \mathrm{H}, \mathrm{CH}_{3}\right), 3.96$ (s, 3H, $\left.\mathrm{OCH}_{3}\right), 4.14(\mathrm{~m}, 2 \mathrm{H}, \mathrm{CHO}), 4.22\left(\mathrm{~m}, 4 \mathrm{H}, \mathrm{CH}_{2} \mathrm{O}\right), 5.82$ (s, $\left.1 \mathrm{H}, \mathrm{CHO}_{2}\right), 7.28-7.37\left(\mathrm{~m}, 6 \mathrm{H}, \mathrm{H}_{\text {arom }}\right), 7.71-7.77(\mathrm{~m}, 4 \mathrm{H}$, $\left.\mathrm{H}_{\text {arom }}\right), 7.97$ (d, $\left.2 \mathrm{H}, J=7.5 \mathrm{~Hz}, \mathrm{H}_{\text {arom }}\right) .{ }^{13} \mathrm{C} \mathrm{NMR}\left(\mathrm{CDCl}_{3}\right) \delta$ (ppm) $21.80\left(\mathrm{~s}, \mathrm{CH}_{3}\right), 52.36\left(\mathrm{~s}, \mathrm{OCH}_{3}\right), 68.51\left(\mathrm{~d}, \mathrm{CH}_{2} \mathrm{O}\right), 75.68$ (d, $\mathrm{CHO}$ ), 103.98 (s, $\mathrm{CHO}_{2}$ ), 126.59 (s, $\mathrm{CH}_{\text {arom}}$ ), 128.10 (s, $\mathrm{CH}_{\text {arom}}$ ), 129.74 (s, $\mathrm{CH}_{\text {arom }}$ ), 130.17 (s, $\mathrm{CH}_{\text {arom }}$ ), 131.23 (s,
$\mathrm{C}_{\text {arom }}$ ),132.14 (s, $\mathrm{C}_{\text {arom }}$ ), 141.12 (s, $\mathrm{C}_{\text {arom}}$ ), 145.61 (s, $\mathrm{C}_{\text {arom}}$ ), $166.71(\mathrm{~s}, \mathrm{C}=\mathrm{O})$. MS (ESI) $\mathrm{m} / z, 577(\mathrm{M}+\mathrm{H})^{+}$, HPLC purity $100 \%$ by ELSD. Anal. Calcd for $\mathrm{C}_{27} \mathrm{H}_{28} \mathrm{O}_{10} \mathrm{~S}_{2}$ : C, 56.24; $\mathrm{H}$, 4.89; S, 11.12. Found: C, 55.65; H, 5.01; S, 11.44 .

4-(4,5-Bis-azidomethyl-1,3-dioxolan-2-yl)benzoic Acid Methyl Ester (5). A solution of ditosyl 4 (1.48 g, $2.5 \mathrm{mmol})$ and sodium azide $(0.97 \mathrm{~g}, 15.0 \mathrm{mmol})$ in DMF $(25 \mathrm{~mL})$ was heated overnight under reflux. The reaction mixture was evaporated under reduced pressure, then the residual solution was coevaporated several times with toluene. The resulting oil was treated with brine $(30 \mathrm{~mL})$ and extracted with ethyl acetate $(3 \times 20$ $\mathrm{mL})$. The combined organic extracts were dried $\left(\mathrm{MgSO}_{4}\right)$ and evaporated under reduced pressure to yield a yellow oil $(0.75$ g, 94\%) that was used without further purification. ${ }^{1} \mathrm{H}$ NMR $\left(\mathrm{CDCl}_{3}\right) \delta(\mathrm{ppm}) 3.49$ and $3.60\left(\mathrm{~m}, 4 \mathrm{H}, \mathrm{CH}_{2}\right), 3.90(\mathrm{~s}, 3 \mathrm{H}$, $\left.\mathrm{OCH}_{3}\right), 4.20(\mathrm{~m}, 2 \mathrm{H}, \mathrm{CHO}), 6.03\left(\mathrm{~s}, 1 \mathrm{H}, \mathrm{CHO}_{2}\right), 7.57$ (d, 2H, $\left.J=8.1 \mathrm{~Hz}, \mathrm{H}_{\text {arom }}\right), 8.06\left(\mathrm{~d}, 2 \mathrm{H}, J=8.1 \mathrm{~Hz}, \mathrm{H}_{\text {arom }}\right) .{ }^{13} \mathrm{C} \mathrm{NMR}$ $\left(\mathrm{CDCl}_{3}\right) \delta(\mathrm{ppm}) 51.88\left(\mathrm{~s}, \mathrm{CH}_{2}\right), 52.24\left(\mathrm{~s}, \mathrm{CH}_{3}\right), 77.54$ and 78.36 (2s, CHO), 103.58 (s, $\mathrm{CHO}_{2}$ ), 126.56 (s, $\mathrm{CH}_{\text {arom }}$ ), 129.83 (s, $\mathrm{CH}_{\text {arom}}$ ), 131.32 (s, $\left.\mathrm{C}_{\text {arom }}\right), 141.57$ (s, $\left.\mathrm{C}_{\text {arom }}\right), 166.72$ (s, $\mathrm{C}=\mathrm{O})$. MS $(\mathrm{ESI}, \mathrm{m} / \mathrm{z}) 378(\mathrm{M}+\mathrm{H})^{+}$, HPLC purity $82 \%$ by ELSD.

4-(4,5-Bis-azidomethyl-1,3-dioxolan-2-yl)benzoic Acid (6). Ester 5 was treated with a solution of sodium hydroxide $(0.64$ g, $16.0 \mathrm{mmol})$ in a mixture of $\mathrm{H}_{2} \mathrm{O} / \mathrm{CH}_{3} \mathrm{OH} / \mathrm{THF}(1: 1: 1 \mathrm{v} / \mathrm{v} / \mathrm{v}$, $45 \mathrm{~mL})$. When all the starting material had disappeared, iced 2 $\mathrm{N} \mathrm{HCl}$ was added to reach $\mathrm{pH} 3$. Then, the reaction mixture was extracted with ethyl acetate $(3 \times 20 \mathrm{~mL})$. The combined organic extracts were washed with brine, dried $\left(\mathrm{MgSO}_{4}\right)$, and evaporated under reduced pressure to give a yellow oil $(0.75 \mathrm{~g}$, $94 \%$ ) that was used without further purification. ${ }^{1} \mathrm{H}$ NMR $\left(\mathrm{CDCl}_{3}\right) \delta(\mathrm{ppm}) 3.44-3.67\left(\mathrm{~m}, 4 \mathrm{H}, \mathrm{CH}_{2}\right), 4.23(\mathrm{~m}, 2 \mathrm{H}, \mathrm{CHO})$, $6.07\left(\mathrm{~s}, 1 \mathrm{H}, \mathrm{CHO}_{2}\right), 7.61\left(\mathrm{~d}, 2 \mathrm{H}, J=8.1 \mathrm{~Hz}, \mathrm{H}_{\text {arom }}\right), 8.15(\mathrm{~d}$, $\left.2 \mathrm{H}, J=8.1 \mathrm{~Hz}, \mathrm{H}_{\text {arom }}\right) .{ }^{13} \mathrm{C} \mathrm{NMR}\left(\mathrm{CDCl}_{3}\right) \delta(\mathrm{ppm}) 51.80(\mathrm{~s}$, $\mathrm{CH}_{2}$ ), 77.54 and 78.36 (s, CHO), 103.48 (s, $\mathrm{CHO}_{2}$ ), 126.71 (s, $\mathrm{CH}_{\text {arom }}$ ), 130.50 (s, $\mathrm{CH}_{\text {arom }}$ ), 131.31 (s, $\mathrm{C}_{\text {arom }}$ ), 142.39 (s, $\mathrm{C}_{\text {arom }}$ ), $171.85(\mathrm{~s}, \mathrm{C}=\mathrm{O})$. MS (ESI, $m / z) 302(\mathrm{M}+\mathrm{HCOO})^{-}$. HPLC purity $98 \%$ by ELSD.

4-(4,5-Bis-azidomethyl-1,3-dioxolan-2-yl)-N,N-ditetradecylbenzamide (7). $N$-methylmorpholin $(0.20 \mathrm{~mL}, 1.8 \mathrm{mmol})$ was added to a THF solution $(30 \mathrm{~mL})$ of $\mathbf{6}(0.54 \mathrm{~g}, 1.8 \mathrm{mmol})$ cooled to $-40{ }^{\circ} \mathrm{C}$. Then, a THF solution $(3 \mathrm{~mL})$ of isobutyl chloroformate $(0.23 \mathrm{~mL}, 1.8 \mathrm{mmol})$ was added slowly. The reaction mixture was stirred for $1 \mathrm{~h}$ at $-40{ }^{\circ} \mathrm{C}$, then a THF solution $(5$ $\mathrm{mL})$ of ditetradecylamine $(0.68 \mathrm{~g}, 1.8 \mathrm{mmol})$ and $N$-methylmorpholin $(0.20 \mathrm{~mL}, 1.8 \mathrm{mmol})$ was added slowly. The resulting mixture was stirred vigorously for $20 \mathrm{~h}$ at RT. Then, ethyl acetate $(150 \mathrm{~mL})$ and water $(150 \mathrm{~mL})$ were added. The water layer was extracted twice with ethyl acetate; then, the combined organic layers were successively washed twice with $1 \mathrm{~N} \mathrm{HCl}$, twice with a saturated solution of $\mathrm{NaHCO}_{3}$, twice with brine, and then dried $\left(\mathrm{MgSO}_{4}\right)$. The solvent was removed under reduced pressure, then the resulting oil was purified by chromatography (heptane/ethyl acetate $1: 4$, then $3: 7$ ) to yield 7 as a clear oil $(0.55 \mathrm{~g}, 46 \%) .{ }^{1} \mathrm{H}$ NMR $\left(\mathrm{CDCl}_{3}\right) \delta(\mathrm{ppm}) 0.87(\mathrm{t}$, 
$\left.6 \mathrm{H}, J=6.9 \mathrm{~Hz}, \mathrm{CH}_{3}\right), 1.21-1.46\left(\mathrm{~m}, 44 \mathrm{H},-\mathrm{CH}_{2}-\right), 1.63(\mathrm{~m}$, $\left.4 \mathrm{H}, \mathrm{CH}_{2}\right), 3.14\left(\mathrm{t}, 2 \mathrm{H}, J=7.2 \mathrm{~Hz}, \mathrm{CH}_{2} \mathrm{~N}\right), 3.38-3.63(\mathrm{~m}, 6 \mathrm{H}$, $\left.\mathrm{CH}_{2} \mathrm{~N}, \mathrm{CH}_{2} \mathrm{~N}_{3}\right), 4.20(\mathrm{~m}, 2 \mathrm{H}, \mathrm{CHO}), 6.01\left(\mathrm{~s}, 1 \mathrm{H}, \mathrm{CHO}_{2}\right), 7.37$ $\left(\mathrm{d}, 2 \mathrm{H}, J=7.1 \mathrm{~Hz}, \mathrm{CH}_{\text {arom }}\right), 7.52\left(\mathrm{~d}, 2 \mathrm{H}, J=7.1 \mathrm{~Hz}, \mathrm{CH}_{\text {arom }}\right)$. ${ }^{13} \mathrm{C} \mathrm{NMR}\left(\mathrm{CDCl}_{3}\right) \delta(\mathrm{ppm}) 14.20\left(\mathrm{~s}, \mathrm{CH}_{3}\right), 22.78\left(\mathrm{~s},-\mathrm{CH}_{2}-\right)$, 27.17 (s, $\left.-\mathrm{CH}_{2}-\right), 28.77$ (s, $\left.-\mathrm{CH}_{2}-\right), 29.73\left(\mathrm{~m},-\mathrm{CH}_{2}-\right)$, $32.01\left(\mathrm{~s},-\mathrm{CH}_{2}-\right), 44.76$ and $49.04\left(2 \mathrm{~s}, \mathrm{CH}_{2} \mathrm{~N}\right), 51.85(\mathrm{~s}$, $\mathrm{CH}_{2} \mathrm{~N}_{3}$ ), 77.80 (d, $\left.\mathrm{CHO}\right), 103.82\left(\mathrm{~s}, \mathrm{CHO}_{2}\right), 126.69$ (s, $\left.\mathrm{CH}_{\text {arom }}\right)$, 137.57 (s, $\mathrm{C}_{\text {arom }}$ ), 138.76 (s, $\left.\mathrm{C}_{\text {arom}}\right), 171.09$ (s, C=O). MS (ESI, $\mathrm{m} / z) 697(\mathrm{M}+\mathrm{H})^{+}$, HPLC purity $99 \%$ by ELSD.

4-(4,5-Bis-aminomethyl-1,3-dioxolan-2-yl)-N,N-ditetradecylbenzamide $(8)$. A $25 \mathrm{~mL}$ round-bottom flask equipped with a magnetic stirring bar was filled successively with diazide 7 (0.35 $\mathrm{g}, 0.5 \mathrm{mmol})$, ethanol $(10 \mathrm{~mL}), \mathrm{Pd} / \mathrm{C}(50 \mathrm{mg})$, and hydrogen. The suspension was stirred for $19 \mathrm{~h}$ at RT, then the mixture was filtered through celite to yield after evaporation the diamine $8(0.31 \mathrm{~g}, 96 \%)$, which was used without further purification. ${ }^{1} \mathrm{H} \mathrm{NMR}\left(\mathrm{CDCl}_{3}\right) \delta(\mathrm{ppm}) 0.84\left(\mathrm{t}, 6 \mathrm{H}, J=6.9 \mathrm{~Hz}, \mathrm{CH}_{3}\right), 1.04-$ $1.46\left(\mathrm{~m}, 44 \mathrm{H},-\mathrm{CH}_{2}-\right), 1.56\left(\mathrm{~m}, 4 \mathrm{H},-\mathrm{CH}_{2}-\right), 2.99-3.40(\mathrm{~m}$, $\left.8 \mathrm{H}, \mathrm{CH}_{2} \mathrm{~N}, \mathrm{CH}_{2} \mathrm{NH}_{2}\right), 4.24$ (m, 2H, CHO), 5.97 (s, $1 \mathrm{H}, \mathrm{CHO}_{2}$ ), $6.40\left(\mathrm{~m}, 4 \mathrm{H}, \mathrm{NH}_{2}\right), 7.28$ (d, $\left.2 \mathrm{H}, J=7.1 \mathrm{~Hz}, \mathrm{CH}_{\text {arom }}\right), 7.55$ (d, $\left.2 \mathrm{H}, J=7.1 \mathrm{~Hz}, \mathrm{CH}_{\text {arom }}\right) .{ }^{13} \mathrm{C} \mathrm{NMR}\left(\mathrm{CDCl}_{3}\right) \delta(\mathrm{ppm}) 14.12(\mathrm{~s}$, $\left.\mathrm{CH}_{3}\right), 22.71\left(\mathrm{~s},-\mathrm{CH}_{2}-\right), 27.25\left(\mathrm{~s},-\mathrm{CH}_{2}-\right), 28.82\left(\mathrm{~s},-\mathrm{CH}_{2}-\right.$ ), $29.73\left(\mathrm{~m},-\mathrm{CH}_{2}-\right), 31.97\left(\mathrm{~s},-\mathrm{CH}_{2}-\right), 41.73\left(\mathrm{~d}, \mathrm{CH}_{2} \mathrm{NH}_{2}\right)$, 45.02 and $49.24\left(2 \mathrm{~s}, \mathrm{CH}_{2}-\mathrm{N}\right), 78.15(\mathrm{~d}, \mathrm{CHO}), 102.87$ (s, $\mathrm{CHO}_{2}$ ), 126.51 (s, $\mathrm{CH}_{\text {arom }}$ ), 127.31 (s, $\left.\mathrm{CH}_{\text {arom }}\right), 138.16$ (s, $\mathrm{C}_{\text {arom }}$ ), $171.29(\mathrm{~s}, \mathrm{C}=\mathrm{O})$. MS (ESI, $m / z) 645(\mathrm{M}+\mathrm{H})^{+}$. HPLC purity $92 \%$ by ELSD.

4-(4,5-Bis-isothiocyanatomethyl-1,3-dioxolan-2-yl)- $N, N$-ditetradecylbenzamide (9). Diisopropylethylamine $(0.26 \mathrm{~mL}, 1.5$ mmol) and carbon disulfide $(0.12 \mathrm{~mL}, 2 \mathrm{mmol})$ were successively added to a solution of diamine $8(0.32 \mathrm{~g}, 0.5 \mathrm{mmol})$ in dichloromethane $(5 \mathrm{~mL})$. The solution was stirred for $90 \mathrm{~min}$, then a solution of tosyl chloride $(0.19 \mathrm{~g}, 1 \mathrm{mmol})$ in dichloromethane was added dropwise. The mixture was stirred for $20 \mathrm{~h}$ at room temperature, diluted with dichloromethane, and washed three times with brine. The organic solution was dried $\left(\mathrm{MgSO}_{4}\right)$ and evaporated under vacuum. The crude was purified by chromatography (heptane/ethyl acetate $8: 2,7: 3$, and $6: 4$ ) to yield 9 as a colorless oil $(0.24 \mathrm{~g}, 66 \%) .{ }^{1} \mathrm{H}$ NMR $\left(\mathrm{CDCl}_{3}\right) \delta$ (ppm) $0.84\left(\mathrm{t}, 6 \mathrm{H}, J=6.9 \mathrm{~Hz}, \mathrm{CH}_{3}\right), 1.04-1.30(\mathrm{~m}, 44 \mathrm{H}$, $\left.-\mathrm{CH}_{2}-\right), 1.46\left(\mathrm{~m}, 4 \mathrm{H},-\mathrm{CH}_{2}-\right), 3.15$ and $3.46\left(\mathrm{~m}, 4 \mathrm{H}, \mathrm{CH}_{2} \mathrm{~N}\right)$, 3.80 and $3.90\left(\mathrm{~m}, 4 \mathrm{H}, \mathrm{CH}_{2} \mathrm{NCS}\right), 4.28(\mathrm{~m}, 2 \mathrm{H}, \mathrm{CHO}), 6.06(\mathrm{~s}$, $\left.1 \mathrm{H}, \mathrm{CHO}_{2}\right), 7.39\left(\mathrm{~d}, 2 \mathrm{H}, J=6.5 \mathrm{~Hz}, \mathrm{CH}_{\text {arom }}\right), 7.53(\mathrm{~d}, 2 \mathrm{H}, J=$ $\left.6.5 \mathrm{~Hz}, \mathrm{CH}_{\text {arom }}\right) .{ }^{13} \mathrm{C} \mathrm{NMR}\left(\mathrm{CDCl}_{3}\right) \delta(\mathrm{ppm}) 14.07\left(\mathrm{~s}, \mathrm{CH}_{3}\right)$, $22.71\left(\mathrm{~s},-\mathrm{CH}_{2}-\right), 27.17\left(\mathrm{~s},-\mathrm{CH}_{2}-\right), 29.04\left(\mathrm{~s},-\mathrm{CH}_{2}-\right), 29.73$ $\left(\mathrm{m},-\mathrm{CH}_{2}-\right), 31.93\left(\mathrm{~s},-\mathrm{CH}_{2}-\right), 44.97$ and $49.19\left(\mathrm{~s},-\mathrm{CH}_{2} \mathrm{~N}\right)$, $46.59\left(\mathrm{CH}_{2} \mathrm{NCS}\right), 77.1$ (d, $\left.\mathrm{CHO}\right), 104.40\left(\mathrm{~s}, \mathrm{CHO}_{2}\right), 126.74(\mathrm{~s}$, $\mathrm{CH}_{\text {arom }}$ ), 132.02 (s, $\left.\mathrm{C}=\mathrm{S}\right), 138.58$ ( $\left.\mathrm{s}, \mathrm{C}_{\text {arom }}\right), 138.83$ (s, $\mathrm{C}_{\text {arom}}$ ), $171.17(\mathrm{~s}, \mathrm{C}=\mathrm{O}) . \mathrm{IR}(\mathrm{NaCl}): \sigma\left(\mathrm{cm}^{-1}\right) 1086\left(\nu_{\mathrm{C}-\mathrm{O}-\mathrm{C}}\right), 1465$ $\left(\delta_{\mathrm{CH}_{2}}\right), 1629\left(v_{\mathrm{C}=\mathrm{O}}\right), 2048\left(v_{\mathrm{N}=\mathrm{C}=\mathrm{S}}\right), 2842\left(v_{=\mathrm{C}-\mathrm{H}_{2}}\right), 2934\left(v_{\mathrm{CH}_{2}}\right)$, $3196\left(\nu=\mathrm{C}-\mathrm{H}_{\text {arom }}\right)$.

4-\{4,5-Bis-[3-(2-hydroxyethyl)thioureidomethyl]-1,3-dioxolan$2-y l\}-N, N$-ditetradecylbenzamide (10). Ethanolamine $(0.026 \mathrm{~mL}$, $0.4 \mathrm{mmol}$ ) was added to a solution of diisothiocyanate 9 (62 $\mathrm{mg}, 0.09 \mathrm{mmol})$ in THF ( $1 \mathrm{~mL})$, then the mixture was stirred for $22 \mathrm{~h}$ at room temperature. The solution was concentrated under reduced pressure. The resulting oil was purified by SPE (C-8 $100 \%$ acetonitrile to $100 \%$ methanol) to afford the dithiourea $10(29.8 \mathrm{mg}, 39 \%)$ as a colorless oil. ${ }^{1} \mathrm{H}$ NMR $\left(\mathrm{CDCl}_{3}\right) \delta(\mathrm{ppm}) 0.87\left(\mathrm{~m}, 6 \mathrm{H}, \mathrm{CH}_{3}\right), 1.25\left(\mathrm{~m}, 44 \mathrm{H},-\mathrm{CH}_{2}-\right)$, $1.62\left(\mathrm{~m}, 4 \mathrm{H},-\mathrm{CH}_{2}-\right), 3.14\left(\mathrm{~m}, 2 \mathrm{H},-\mathrm{CH}_{2} \mathrm{NCO}\right), 3.44-3.78$ (m, $\left.14 \mathrm{H},-\mathrm{CH}_{2} \mathrm{NCO}, \mathrm{CH}_{2} \mathrm{NCS}, \mathrm{CH}_{2} \mathrm{OH}\right), 4.16(\mathrm{~m}, 2 \mathrm{H}, \mathrm{CHO})$, $5.94\left(\mathrm{~s}, 1 \mathrm{H}, \mathrm{CHO}_{2}\right), 7.25(\mathrm{~m}, 4 \mathrm{H}, \mathrm{NH}), 7.33\left(\mathrm{~m}, 2 \mathrm{H}, \mathrm{CH}_{\text {arom }}\right)$, $7.52\left(\mathrm{~m}, 2 \mathrm{H}, \mathrm{CH}_{\text {arom }}\right) .{ }^{13} \mathrm{C} \mathrm{NMR}\left(\mathrm{CDCl}_{3}\right) \delta(\mathrm{ppm}) 14.09(\mathrm{~s}$, $\left.\mathrm{CH}_{3}\right), 22.71\left(\mathrm{~s},-\mathrm{CH}_{2}-\right), 27.22\left(\mathrm{~s},-\mathrm{CH}_{2}-\right), 28.83\left(\mathrm{~s},-\mathrm{CH}_{2}-\right.$ ), 29.73 (m, $\left.-\mathrm{CH}_{2}-\right), 31.97$ (s, $\left.-\mathrm{CH}_{2}-\right), 45.30$ (s, $\left.\mathrm{CH}_{2} \mathrm{NCS}\right)$, $45.80\left(\mathrm{~s}, \mathrm{CH}_{2} \mathrm{NCS}\right), 46.97$ and 49.45 (s, $\left.\mathrm{CH}_{2} \mathrm{NCO}\right), 61.42$ (s, $\mathrm{CH}_{2} \mathrm{OH}$ ), 78.23 (d, CHO), 102.83 (s, $\left.\mathrm{CHO}_{2}\right), 126.48$ (s, $\mathrm{CH}_{\text {arom }}$ ), $127.05\left(\mathrm{~s}, \mathrm{CH}_{\text {arom }}\right) 138.14\left(\mathrm{~s}, \mathrm{C}_{\text {arom }}\right), 138.80\left(\mathrm{~s}, \mathrm{C}_{\text {arom}}\right), 171.71$ $(\mathrm{s}, \mathrm{C}=\mathrm{O}), 183.35(\mathrm{~s}, \mathrm{C}=\mathrm{S})$.

$N, N$-ditetradecyl-4-(4,5-bis-azidomethyl-1,3-dioxolan-2-yl)benzamide (11). 3-Amino-1,2-propanediol (22 mg, $0.24 \mathrm{mmol}$ ) was added to a solution of $9(41 \mathrm{mg}, 0.056 \mathrm{mmol})$ in dry DMF. The solution was stirred at RT for $20 \mathrm{~h}$ then concentrated to dryness. The crude was dissolved in ethyl acetate and washed three times with brine. The organic layer was dried $\left(\mathrm{MgSO}_{4}\right)$ and evaporated to dryness. Purification as for $\mathbf{1 0}$ gave $\mathbf{1 1}$ as a colorless oil $(20 \mathrm{mg}, 38 \%) .{ }^{1} \mathrm{H}$ NMR $\left(\mathrm{CDCl}_{3}\right) \delta$ (ppm) 0.88 $\left(\mathrm{m}, 6 \mathrm{H}, \mathrm{CH}_{3}\right), 1.27\left(\mathrm{~m}, 44 \mathrm{H},-\mathrm{CH}_{2}-\right), 1.65\left(\mathrm{~m}, 4 \mathrm{H},-\mathrm{CH}_{2}-\right)$, $3.16\left(\mathrm{~m}, 2 \mathrm{H},-\mathrm{CH}_{2} \mathrm{NCO}\right), 3.35-3.48\left(\mathrm{~m}, 6 \mathrm{H},-\mathrm{CH}_{2} \mathrm{NCO}, \mathrm{CH}_{2-}\right.$ $\mathrm{NCS}), 3.47-3.68\left(\mathrm{~m}, 8 \mathrm{H}, \mathrm{CH}_{2} \mathrm{NCS}, \mathrm{CH}_{2} \mathrm{OH}\right), 3.97(\mathrm{~m}$, $2 \mathrm{H}, \mathrm{CHOH}), 4.16(\mathrm{~m}, 2 \mathrm{H}, \mathrm{CHO}), 5.97\left(\mathrm{~s}, 1 \mathrm{H}, \mathrm{CHO}_{2}\right), 7.35(\mathrm{~m}$, $\left.2 \mathrm{H}, \mathrm{CH}_{\text {arom }}\right), 7.55\left(\mathrm{~m}, 2 \mathrm{H}, \mathrm{CH}_{\text {arom }}\right) .{ }^{13} \mathrm{C} \mathrm{NMR}\left(\mathrm{CDCl}_{3}\right) \delta$ (ppm) $13.96\left(\mathrm{~s}, \mathrm{CH}_{3}\right), 22.64\left(\mathrm{~s},-\mathrm{CH}_{2}-\right), 27.11$ (s, $\left.-\mathrm{CH}_{2}-\right)$, 28.78 (s, $\left.-\mathrm{CH}_{2}-\right), 29.73\left(\mathrm{~m},-\mathrm{CH}_{2}-\right), 31.91\left(\mathrm{~s},-\mathrm{CH}_{2}-\right)$, 45.27 (s, $\left.-\mathrm{CH}_{2} \mathrm{NCS}\right), 45.83\left(\mathrm{~s},-\mathrm{CH}_{2} \mathrm{NCS}\right), 46.91$ and 49.44 (s, $\left.-\mathrm{CH}_{2} \mathrm{NCO}\right), 63.65$ (s, $\left.\mathrm{CH}_{2} \mathrm{OH}\right), 70.99$ (s, CHOH), 78.33 (d, $\mathrm{CHO}$ ), 102.88 (s, $\left.\mathrm{CHO}_{2}\right), 126.42$ (s, $\left.\mathrm{CH}_{\text {arom }}\right), 126.86$ (s, $\mathrm{CH}_{\text {arom }}$ ), 138.02 (s, $\left.\mathrm{C}_{\text {arom }}\right), 138.72$ (s, $\left.\mathrm{C}_{\text {arom }}\right), 171.87$ (s, $\mathrm{C}=\mathrm{O}$ ), 183.49 (s, C $=$ S). ES-HRMS Calcd. for $\mathrm{C}_{48} \mathrm{H}_{87} \mathrm{~N}_{5} \mathrm{O}_{7} \mathrm{NaS}_{2}$ : 932.5945. Found: 932.5965.

2-(2-\{2-[2-(2,2-Diethoxyethoxy)ethoxy]ethoxy\}ethoxy)tetrahydropyran (13). Sodium hydride $(1.7 \mathrm{~g}, 43 \mathrm{mmol})$ was added portionwise to an iced cooled solution of $\mathbf{1 2}$ (previously dried by codistillation with THF) in THF $(50 \mathrm{~mL})$. The suspension was stirred for $30 \mathrm{~min}$, then bromoacetaldehyde diethylacetal $(2.3 \mathrm{~mL}, 17 \mathrm{mmol})$ was added dropwise. The mixture was stirred for $3 \mathrm{~h}$ at RT, then heated overnight at 60 ${ }^{\circ} \mathrm{C}$. The reaction mixture was cooled with an ice bath, then the reaction was stopped by the addition of water $(2 \mathrm{~mL})$. Most of the solvent was removed by evaporation under reduced pressure, then water and dichloromethane were added. The water layer was extracted three times with dichloromethane, then the combined organic layer was washed with brine, dried $\left(\mathrm{MgSO}_{4}\right)$, and concentrated under reduced pressure. The residual oil was purified by chromatography (heptane/ethyl acetate 1:1) to afford 13 (3 g, 100\%), which was used without further purification. ${ }^{1} \mathrm{H}$ NMR $\left(\mathrm{CDCl}_{3}\right) \delta(\mathrm{ppm}) 1.11\left(\mathrm{t}, 6 \mathrm{H}, J=6.9 \mathrm{~Hz}, \mathrm{CH}_{3}\right)$, 1.41-1.72 (m, 6H, $-\mathrm{CH}_{2}$-ring), $3.43\left(\mathrm{~m}, 4 \mathrm{H}, \mathrm{OCH}_{2}-\mathrm{CH}_{3}\right)$, $3.48\left(\mathrm{~m}, 2 \mathrm{H}, \mathrm{CH}_{2} \mathrm{O}-\right.$ ring), $3.53-3.59\left(\mathrm{~m}, 12 \mathrm{H},-\mathrm{CH}_{2} \mathrm{O}-\right), 3.75$ $\left(\mathrm{m}, 2 \mathrm{H}, \mathrm{CH}_{2}-\mathrm{CH}\right), 4.53\left(\mathrm{~m}, 2 \mathrm{H}, \mathrm{CHO}_{2}\right) .{ }^{13} \mathrm{C} \mathrm{NMR}\left(\mathrm{CDCl}_{3}\right) \delta$ (ppm) $15.32\left(\mathrm{~s}, \mathrm{CH}_{3}\right), 19.45\left(\mathrm{~s}, \mathrm{CH}_{2}-\right.$ ring), 25.46 (s, $\mathrm{CH}_{2}$-ring), 30.58 (s, $\mathrm{CH}_{2}-$ ring), 62.21 ( $-\mathrm{CH}_{2} \mathrm{O}-$ ), 66.64 ( $\mathrm{CH}_{2} \mathrm{O}$-ring), 70.62 (s, $\left.-\mathrm{CH}_{2} \mathrm{O}-\right), 70.91$ (s, $\left.-\mathrm{CH}_{2} \mathrm{O}-\right), 71.95$ (s, $-\mathrm{CH}_{2} \mathrm{O}-$ ) $, 98.86\left(\mathrm{~s}, \mathrm{CHO}_{2}\right), 101.22\left(\mathrm{~s}, \mathrm{CHO}_{2}\right)$. MS (ESI, $\mathrm{m} / \mathrm{z}) 373(\mathrm{M}+\mathrm{H})^{+}$. Anal. Calcd for $\mathrm{C}_{17} \mathrm{H}_{34} \mathrm{O}_{7}$ : C, 58.26; $\mathrm{H}$, 97.8; Found: C, 57.79; H, 9.90.

2-\{2-[2-(4,5-Bis-(toluene-4-sulfonyloxymethyl)-[1,3]-dioxolan2-ylmethoxy)ethoxy]ethoxy\}ethanol (14). Ditosyl 2 (0.28 g, 0.65 $\mathrm{mmol})$ and para-toluenesulfonic acid $(0.022 \mathrm{~g}, 0.13 \mathrm{mmol})$ was added to a solution of $\mathbf{1 3}(0.23 \mathrm{~g}, 0.65 \mathrm{mmol})$ in benzene (10 $\mathrm{mL}$ ), then the solution was heated to reflux for $22 \mathrm{~h}$. Pyridine $(0.1 \mathrm{~mL})$ was added at $\mathrm{RT}$, then the solvent was removed under reduced pressure, and the residual oil was purified to yield a mixture of the acetals protected by THP $(0.14 \mathrm{~g}, 31 \%)$ or with free hydroxyl terminus $14(0.096 \mathrm{~g}, 24 \%)$. After dissolution of the THP-protected compound in methanol $(2 \mathrm{~mL})$, paratoluenesulfonic acid was added to the solution, and the reaction mixture was stirred for $6 \mathrm{~h}$, then poured in an Erlenmeyer flask filled with solid potassium carbonate. The solution was filtered, and the filtrate was concentrated under reduced pressure. The residual oil was dissolved in dichloromethane and washed three times with a saturated $\mathrm{NaHCO}_{3}$ solution and brine successively. 
Then, the solvent was removed under reduced pressure to afford the alcohol 14. The total yield for the reaction was 52\% (65 $\mathrm{mg}) .{ }^{1} \mathrm{H} \mathrm{NMR}\left(\mathrm{CDCl}_{3}\right) \delta(\mathrm{ppm}) 2.46\left(\mathrm{~s}, 6 \mathrm{H}, \mathrm{CH}_{3}\right), 2.85(\mathrm{~m}$, $1 \mathrm{H}, \mathrm{OH}), 3.47\left(\mathrm{~d}, 2 \mathrm{H}, J=4.6 \mathrm{~Hz}, \mathrm{CH}_{2} \mathrm{O}\right), 3.60-3.65(\mathrm{~m}, 10 \mathrm{H}$, $-\mathrm{CH}_{2} \mathrm{O}-$ ), $3.71\left(\mathrm{~m}, 2 \mathrm{H},-\mathrm{CH}_{2} \mathrm{OH}\right), 4.07-4.13$ (m, 6H, CHO, $\mathrm{CH}_{2} \mathrm{OS}$ ), 5.11 (t, $1 \mathrm{H}, J=3.3 \mathrm{~Hz}, \mathrm{CHO}_{2}$ ), 7.36 (d, $2 \mathrm{H}, J=8.1$ $\left.\mathrm{Hz}, \mathrm{CH}_{\text {arom }}\right), 7.78$ (d, $\left.2 \mathrm{H}, J=8.1 \mathrm{~Hz}, \mathrm{CH}_{\text {arom }}\right) .{ }^{13} \mathrm{C} \mathrm{NMR}$ $\left(\mathrm{CDCl}_{3}\right) \delta(\mathrm{ppm}) 21.67\left(\mathrm{~s}, \mathrm{CH}_{3}\right), 61.84\left(\mathrm{~s}, \mathrm{CH}_{2} \mathrm{OH}\right), 66.33(\mathrm{~d}$, $\mathrm{CH}_{2} \mathrm{OS}$ ), $70.56\left(\mathrm{~s},-\mathrm{CH}_{2} \mathrm{O}-\right), 70.69$ (s, $\left.-\mathrm{CH}_{2} \mathrm{O}-\right), 71.26(\mathrm{~s}$, $\left.-\mathrm{CH}_{2} \mathrm{O}-\right), 71.88$ (s, $\left.-\mathrm{CH}_{2} \mathrm{O}-\right), 72.54\left(\mathrm{~s},-\mathrm{CH}_{2} \mathrm{O}-\right), 75.67$ (s, CHO), $104.16\left(\mathrm{~s}, \mathrm{CHO}_{2}\right), 128.05$ (s, $\left.\mathrm{CH}_{\text {arom}}\right), 130.06$ (s, $\mathrm{CH}_{\text {arom }}$ ), 132.71 (s, $\left.\mathrm{C}_{\text {arom}}\right), 145.28$ (s, $\left.\mathrm{C}_{\text {arom }}\right) . \mathrm{MS}(\mathrm{ESI}, \mathrm{m} / \mathrm{z}) 605$ $(\mathrm{M}+\mathrm{H})^{+}$.

\{2-[2-(4,5-Bis(toluene-4-sulfonyloxymethyl)-[1,3]-dioxolan2-ylmethoxy)ethoxy]ethoxy \}acetic acid (15). Alcohol 14 (0.145 $\mathrm{g}, 0.24 \mathrm{mmol})$ was dissolved in acetone $(2.5 \mathrm{~mL})$. A solution of $\mathrm{NaHCO}_{3}(15 \%$ in water, $0.75 \mathrm{~mL})$ was added, and the reaction mixture was cooled to $0{ }^{\circ} \mathrm{C}$. Then, sodium bromide $(5$ $\mathrm{mg}, 0.05 \mathrm{mmol}$ ), TEMPO (4 mg, $0.024 \mathrm{mmol}$ ), and trichloroisocyanuric acid $(0.11 \mathrm{~g}, 0.48 \mathrm{mmol})$ were successively added. The reaction mixture was stirred vigorously for $14 \mathrm{~h}$, and isopropanol $(0.14 \mathrm{~mL})$ was added to stop the reaction. After filtration, the solvent was evaporated under reduced pressure to yield a solid that was dissolved in a saturated solution of $\mathrm{Na}_{2} \mathrm{CO}_{3}$. The solution was extracted three times with ethyl acetate, dried $\left(\mathrm{MgSO}_{4}\right)$, and evaporated under reduced pressure to give the acid 15 as a yellow oil $(0.106 \mathrm{~g}, 71 \%) .{ }^{1} \mathrm{H}$ NMR $\left(\mathrm{CDCl}_{3}\right) \delta(\mathrm{ppm}) 2.40\left(\mathrm{~s}, 6 \mathrm{H}, \mathrm{CH}_{3}\right), 3.41(\mathrm{~d}, 2 \mathrm{H}, J=4.6 \mathrm{~Hz}$, $-\mathrm{CH}_{2} \mathrm{O}-$ ) , 3.57-3.68 (m, 8H, $-\mathrm{CH}_{2} \mathrm{O}-$ ), 4.05 (m, 6H, CHO, $\mathrm{CH}_{2} \mathrm{OS}$ ), 4.10 (s, $\left.2 \mathrm{H}, \mathrm{CH}_{2} \mathrm{CO}\right), 5.05\left(\mathrm{t}, 1 \mathrm{H}, J=3.3 \mathrm{~Hz}, \mathrm{CHO}_{2}\right.$ ), $7.31\left(\mathrm{~d}, 2 \mathrm{H}, J=8.1 \mathrm{~Hz}, \mathrm{CH}_{\text {arom }}\right), 7.72(\mathrm{~d}, 2 \mathrm{H}, J=8.1 \mathrm{~Hz}$, $\left.\mathrm{CH}_{\text {arom}}\right) .{ }^{13} \mathrm{C} \mathrm{NMR}\left(\mathrm{CDCl}_{3}\right) \delta(\mathrm{ppm}) 21.65\left(\mathrm{~s}, \mathrm{CH}_{3}\right), 61.42(\mathrm{~d}$, $\mathrm{CH}_{2} \mathrm{OS}$ ), 70.35 (s, $-\mathrm{CH}_{2} \mathrm{O}-$ ), 70.50 (s, $-\mathrm{CH}_{2} \mathrm{O}-$ ), 71.08 (s, $-\mathrm{CH}_{2} \mathrm{O}-$ ), 71.67 (s, $-\mathrm{CH}_{2} \mathrm{O}-$ ), 75.61 (m, $\mathrm{CHO}, \mathrm{CH}_{2} \mathrm{CO}$ ), 104.01 (s, $\mathrm{CHO}_{2}$ ), 128.00 (s, $\mathrm{CH}_{\text {arom}}$ ), 132.37 (s, $\mathrm{CH}_{\text {arom }}$ ), 133.87 (s, $\left.\mathrm{C}_{\text {arom }}\right), 145.28\left(\mathrm{~s}, \mathrm{C}_{\text {arom}}\right), 173.01(\mathrm{~s}, \mathrm{C}=\mathrm{O}) . \mathrm{MS}(\mathrm{ESI}, \mathrm{m} / \mathrm{z})$ $619(\mathrm{M}+\mathrm{H})^{+}$.

2-\{2-[2-(4,5-Bis(toluene-4-sulfonyloxymethyl)-[1,3]-dioxolan2-ylmethoxy)ethoxy]ethoxy\}-N,N-ditetradecylacetamide (16). $\mathrm{N}$ methylmorpholin $(0.21 \mu \mathrm{L}, 0.19 \mathrm{mmol})$ was added to a $\mathrm{THF}$ solution $(4 \mathrm{~mL})$ of $\mathbf{1 5}(0.54 \mathrm{~g}, 1.8 \mathrm{mmol})$ cooled to $-40{ }^{\circ} \mathrm{C}$. Then, a THF solution $(0.5 \mathrm{~mL})$ of isobutyl chloroformate $(0.24$ $\mu \mathrm{L}, 0.19 \mathrm{mmol}$ ) was added slowly. The reaction mixture was stirred for $1 \mathrm{~h}$ at $-40{ }^{\circ} \mathrm{C}$, then a THF solution $(0.5 \mathrm{~mL})$ of ditetradecylamine $(0.07 \mathrm{~g}, 0.17 \mathrm{mmol})$ and $\mathrm{N}$-methylmorpholin $(0.21 \mu \mathrm{L}, 0.19 \mathrm{mmol})$ was added slowly. The resulting mixture was stirred vigorously at RT for $20 \mathrm{~h}$. Then, ethyl acetate (10 $\mathrm{mL})$ and water $(10 \mathrm{~mL})$ were added. The water layer was extracted twice with ethyl acetate, then the combined organic solutions were successively washed twice with $1 \mathrm{~N} \mathrm{HCl}$, twice with a saturated solution of $\mathrm{NaHCO}_{3}$, twice with brine, and then dried $\left(\mathrm{MgSO}_{4}\right)$. The solvent was removed under reduced pressure, then the resulting oil was purified by SFC to yield $\mathbf{1 6}$ as a clear oil $(0.072 \mathrm{~g}, 42 \%) .{ }^{1} \mathrm{H} \mathrm{NMR}\left(\mathrm{CDCl}_{3}\right) \delta(\mathrm{ppm}) 0.86$ $\left(\mathrm{t}, 6 \mathrm{H}, J=6.6 \mathrm{~Hz},-\mathrm{CH}_{3}\right), 1.20-1.32\left(\mathrm{~m}, 44 \mathrm{H},-\mathrm{CH}_{2}-\right), 1.49$ $\left(\mathrm{m}, 4 \mathrm{H},-\mathrm{CH}_{2}-\right), 2.44\left(\mathrm{~s}, 6 \mathrm{H}, \mathrm{CH}_{3}\right), 3.15$ and $3.26(\mathrm{t}, 4 \mathrm{H}, J=$ $\left.7.5 \mathrm{~Hz},-\mathrm{CH}_{2} \mathrm{~N}\right), 3.42\left(\mathrm{~d}, 2 \mathrm{H}, J=4.6 \mathrm{~Hz},-\mathrm{CH}_{2} \mathrm{O}\right), 3.58-$ $3.68\left(\mathrm{~m}, 8 \mathrm{H},-\mathrm{CH}_{2} \mathrm{O}-\right), 4.01-4.09\left(\mathrm{~m}, 6 \mathrm{H}, \mathrm{CHO}, \mathrm{CH}_{2} \mathrm{OS}\right)$, 4.16 (s, 2H, $\mathrm{CH}_{2} \mathrm{CO}$ ), 5.07 (t, $\left.1 \mathrm{H}, J=3.6 \mathrm{~Hz}, \mathrm{CHO}_{2}\right), 7.35$ (d, $\left.J=8.1 \mathrm{~Hz}, \mathrm{CH}_{\text {arom }}\right), 7.75\left(\mathrm{~d}, J=8.1 \mathrm{~Hz}, \mathrm{CH}_{\text {arom }}\right) .{ }^{13} \mathrm{C} \mathrm{NMR}$ $\left(\mathrm{CDCl}_{3}\right) \delta(\mathrm{ppm}) 14.14\left(\mathrm{~s},-\mathrm{CH}_{3}\right), 21.69\left(\mathrm{~s}, \mathrm{CH}_{3}\right), 22.72(\mathrm{~s}$, $-\mathrm{CH}_{2}-$ ), $27.11\left(\mathrm{~s},-\mathrm{CH}_{2}-\right), 29.03\left(\mathrm{~s},-\mathrm{CH}_{2}-\right), 29.69(\mathrm{~m}$, $\left.-\mathrm{CH}_{2}-\right), 31.97\left(\mathrm{~s},-\mathrm{CH}_{2}-\right), 45.86$ and $47.03\left(\mathrm{~s},-\mathrm{CH}_{2} \mathrm{~N}\right)$, 68.25 (d, s, $\left.\mathrm{CH}_{2} \mathrm{OS}\right), 70.07$ (s, $\left.-\mathrm{CH}_{2} \mathrm{O}-\right), 70.58\left(\mathrm{~m},-\mathrm{CH}_{2} \mathrm{O}-\right.$ ), 71.27 ( $\mathrm{s},-\mathrm{CH}_{2} \mathrm{O}-$ ), 71.88 (s, $-\mathrm{CH}_{2} \mathrm{O}-$ ), 75.60 (s, $\mathrm{CHO}$ ), 104.16 (s, $\left.\mathrm{CHO}_{2}\right), 128.06$ (s, $\left.\mathrm{CH}_{\text {arom }}\right), 130.09$ (s, $\mathrm{CH}_{\text {arom }}$ ), 133.66 (s, $\mathrm{C}_{\text {arom}}$ ), 145.31 (s, $\left.\mathrm{C}_{\text {arom}}\right), 168.69$ (s, C=O). MS (ESI, $\left.m / z\right)$ $1011(\mathrm{M}+\mathrm{H})^{+}$.

2-\{2-[2-(4,5-Bis-azidomethyl-[1,3]-dioxolan-2-ylmethoxy)ethoxy] ethoxy\}-N,N-ditetradecylacetamide (17). A solution of ditosyl 16 (0.36 g, $0.36 \mathrm{mmol})$ and sodium azide $(0.23 \mathrm{~g}, 3.60$ $\mathrm{mmol})$ in DMF $(10 \mathrm{~mL})$ was heated overnight under reflux. The reaction mixture was evaporated under reduced pressure, then the residual solution was coevaporated several times with toluene. The resulting oil was treated with brine $(30 \mathrm{~mL})$ and extracted with ethyl acetate $(3 \times 20 \mathrm{~mL})$. The combined organic extracts were dried $\left(\mathrm{MgSO}_{4}\right)$ and evaporated under reduced pressure to yield a yellow oil $(0.28 \mathrm{~g}, 100 \%)$ that was used without further purification. ${ }^{1} \mathrm{H} \mathrm{NMR}\left(\mathrm{CDCl}_{3}\right) \delta(\mathrm{ppm}) 0.86(\mathrm{t}$, $\left.6 \mathrm{H}, J=6.6 \mathrm{~Hz}, \mathrm{CH}_{3}\right), 1.20-1.32\left(\mathrm{~m}, 44 \mathrm{H},-\mathrm{CH}_{2}-\right), 1.52(\mathrm{~m}$, $\left.4 \mathrm{H},-\mathrm{CH}_{2}-\right), 3.16$ and $3.27\left(\mathrm{t}, 4 \mathrm{H}, J=7.5 \mathrm{~Hz},-\mathrm{CH}_{2} \mathrm{~N}\right)$, $3.38-3.55\left(\mathrm{~m}, 4 \mathrm{H}, \mathrm{CH}_{2} \mathrm{~N}_{3}\right), 3.61\left(\mathrm{~d}, 2 \mathrm{H}, J=4.6 \mathrm{~Hz},-\mathrm{CH}_{2} \mathrm{O}\right)$, $3.68\left(\mathrm{~m}, 8 \mathrm{H},-\mathrm{CH}_{2} \mathrm{O}-\right), 4.05(\mathrm{~m}, 2 \mathrm{H}, \mathrm{CHO}), 4.17(\mathrm{~s}, 2 \mathrm{H}$, $\left.-\mathrm{CH}_{2} \mathrm{CO}\right), 5.26\left(\mathrm{t}, 1 \mathrm{H}, J=3.6 \mathrm{~Hz}, \mathrm{CHO}_{2}\right) .{ }^{13} \mathrm{C} \mathrm{NMR}\left(\mathrm{CDCl}_{3}\right)$ $\delta(\mathrm{ppm}) 14.05\left(\mathrm{~s}, \mathrm{CH}_{3}\right), 22.65\left(\mathrm{~s},-\mathrm{CH}_{2}-\right), 26.90\left(\mathrm{~s},-\mathrm{CH}_{2}-\right)$, $28.07\left(\mathrm{~s},-\mathrm{CH}_{2}-\right), 29.69\left(\mathrm{~m},-\mathrm{CH}_{2}-\right), 31.90\left(\mathrm{~s},-\mathrm{CH}_{2}-\right)$, 45.79 and $46.99\left(2 \mathrm{~s},-\mathrm{CH}_{2} \mathrm{~N}\right), 49.96\left(\mathrm{~s},-\mathrm{CH}_{2} \mathrm{~N}_{3}\right), 70.13(\mathrm{~s}$, $-\mathrm{CH}_{2} \mathrm{O}-$ ), 70.56 (m, $-\mathrm{CH}_{2} \mathrm{O}-$ ), 71.24 (s, $\left.-\mathrm{CH}_{2} \mathrm{O}-\right), 72.07$ (s, $-\mathrm{CH}_{2} \mathrm{O}-$ ), 77.12 (d, $\left.\mathrm{CHO}\right), 103.66\left(\mathrm{~s}, \mathrm{CHO}_{2}\right), 162.49$ (s, $\mathrm{C}=\mathrm{O})$.

2-\{2-[2-(4,5-Bis-aminomethyl-[1,3]-dioxolan-2-ylmethoxy)ethoxy]ethoxy\}- $N, N$-ditetradecylacetamide (18). A $25 \mathrm{~mL}$ roundbottom flask equipped with a magnetic stirring bar was filled successively with diazide $17(0.30 \mathrm{~g}, 0.4 \mathrm{mmol})$, ethanol (10 $\mathrm{mL}), \mathrm{Pd} / \mathrm{C}(50 \mathrm{mg})$, and hydrogen. The suspension was stirred for $19 \mathrm{~h}$ at RT, then the mixture was filtered through celite to yield after evaporation the diamine $18(0.304 \mathrm{~g}, 100 \%)$, which was used without further purification. ${ }^{1} \mathrm{H} \mathrm{NMR}\left(\mathrm{CDCl}_{3}\right) \delta(\mathrm{ppm})$ $0.80\left(\mathrm{t}, 6 \mathrm{H}, J=6.6 \mathrm{~Hz}, \mathrm{CH}_{3}\right), 1.20-1.32\left(\mathrm{~m}, 44 \mathrm{H},-\mathrm{CH}_{2}-\right)$, $1.45\left(\mathrm{~m}, 4 \mathrm{H},-\mathrm{CH}_{2}-\right), 2.50(\mathrm{~m}, 4 \mathrm{H}, \mathrm{NH}), 2.78-2.93(\mathrm{~m}, 4 \mathrm{H}$, $\left.\mathrm{CH}_{2} \mathrm{NH}_{2}\right), 3.09$ and $3.20\left(\mathrm{t}, 4 \mathrm{H}, J=7.5 \mathrm{~Hz},-\mathrm{CH}_{2} \mathrm{~N}\right), 3.53(\mathrm{~d}$, $\left.2 \mathrm{H}, J=4.6 \mathrm{~Hz},-\mathrm{CH}_{2} \mathrm{O}\right), 3.59-3.63\left(\mathrm{~m}, 8 \mathrm{H},-\mathrm{CH}_{2} \mathrm{O}-\right), 4.09$ (m, 2H, CHO), $4.12\left(\mathrm{~s}, 2 \mathrm{H}, \mathrm{CH}_{2} \mathrm{CO}\right), 5.14(\mathrm{t}, 1 \mathrm{H}, J=3.6 \mathrm{~Hz}$, $\left.\mathrm{CHO}_{2}\right) .{ }^{13} \mathrm{C} \mathrm{NMR}\left(\mathrm{CDCl}_{3}\right) \delta(\mathrm{ppm}) 14.11\left(\mathrm{~s}, \mathrm{CH}_{3}\right), 22.69(\mathrm{~s}$, $-\mathrm{CH}_{2}-$ ), 27.05 (s, $-\mathrm{CH}_{2}-$ ), 28.06 (s, $\left.-\mathrm{CH}_{2}-\right), 29.69$ (m, $\left.-\mathrm{CH}_{2}-\right), 31.93\left(\mathrm{~s},-\mathrm{CH}_{2}-\right), 43.66\left(\mathrm{~s}, \mathrm{CH}_{2} \mathrm{NH}_{2}\right), 45.87$ and $46.98\left(\mathrm{~s},-\mathrm{CH}_{2} \mathrm{~N}\right), 69.88\left(\mathrm{~s},-\mathrm{CH}_{2} \mathrm{O}-\right), 70.55\left(\mathrm{~m},-\mathrm{CH}_{2} \mathrm{O}-\right)$, 71.17 (s, $\mathrm{CH}_{2} \mathrm{CO}$ ), 72.44 (s, $-\mathrm{CH}_{2} \mathrm{O}-$ ), 80.50 (d, $\mathrm{CHO}$ ), 102.33 (s, $\left.\mathrm{CHO}_{2}\right), 168.69$ (s, $\left.\mathrm{C}=\mathrm{O}\right)$.

2-\{2-[2-(4,5-Bis-isothiocyanatomethyl-[1,3]-dioxolan-2-ylmethoxy)ethoxy]ethoxy $\}-N, N$-ditetradecylacetamide (19). Diisopropylethylamine $(0.18 \mathrm{~mL}, 1 \mathrm{mmol})$ and carbon disulfide $(0.084 \mathrm{~mL}, 1.4 \mathrm{mmol})$ were successively added to a solution of diamine $18(0.26 \mathrm{~g}, 0.35 \mathrm{mmol})$ in dichloromethane $(5 \mathrm{~mL})$. The solution was stirred for $90 \mathrm{~min}$, then a solution of tosyl chloride $(0.13 \mathrm{~g}, 0.7 \mathrm{mmol})$ in dichloromethane $(3 \mathrm{~mL})$ was added dropwise. The mixture was stirred for $20 \mathrm{~h}$, then evaporated under reduced pressure. The crude was purified by SFC to yield 19 as a colorless oil $(0.096 \mathrm{~g}, 35 \%) .{ }^{1} \mathrm{H}$ NMR $\left(\mathrm{CDCl}_{3}\right) \delta(\mathrm{ppm}) 0.87\left(\mathrm{t}, 6 \mathrm{H}, J=6.6 \mathrm{~Hz}, \mathrm{CH}_{3}\right), 1.22-1.29(\mathrm{~m}$, $\left.44 \mathrm{H},-\mathrm{CH}_{2}-\right), 1.51\left(\mathrm{~m}, 4 \mathrm{H},-\mathrm{CH}_{2}-\right), 3.13$ and $3.28(\mathrm{t}, 4 \mathrm{H}, J$ $\left.=7.5 \mathrm{~Hz},-\mathrm{CH}_{2} \mathrm{~N}\right), 3.62\left(\mathrm{~d}, 2 \mathrm{H}, J=4.3 \mathrm{~Hz},-\mathrm{CH}_{2} \mathrm{O}-\right), 3.65-$ $3.73\left(\mathrm{~m}, 8 \mathrm{H},-\mathrm{CH}_{2} \mathrm{O}-\right), 3.79-3.84\left(\mathrm{~m}, 4 \mathrm{H},-\mathrm{CH}_{2} \mathrm{NCS}\right), 4.16$ (m, 2H, CHO), 4.18 (s, 2H, $-\mathrm{CH} 2 \mathrm{CO}-), 5.34(\mathrm{t}, 1 \mathrm{H}, J=3.6$ $\left.\mathrm{Hz}, \mathrm{CHO}_{2}\right) .{ }^{13} \mathrm{C} \mathrm{NMR}\left(\mathrm{CDCl}_{3}\right) \delta(\mathrm{ppm}) 14.14\left(\mathrm{~s}, \mathrm{CH}_{3}\right), 22.70$ (s, $-\mathrm{CH}_{2}-$ ), 27.07 (s, $\left.-\mathrm{CH}_{2}-\right), 28.96\left(\mathrm{~s},-\mathrm{CH}_{2}-\right), 29.67$ (m, $\left.-\mathrm{CH}_{2}-\right), 31.93\left(\mathrm{~s},-\mathrm{CH}_{2}-\right), 45.87$ and $46.44\left(\mathrm{~s},-\mathrm{CH}_{2} \mathrm{~N}\right)$, $46.94\left(\mathrm{~s},-\mathrm{CH}_{2} \mathrm{NCS}\right), 69.88\left(\mathrm{~s},-\mathrm{CH}_{2} \mathrm{O}-\right), 70.51\left(\mathrm{~m},-\mathrm{CH}_{2} \mathrm{O}-\right.$ ), 71.32 (s, $\mathrm{CH}_{2} \mathrm{CO}$ ), 71.83 (s, $-\mathrm{CH}_{2} \mathrm{O}-$ ), 77.03 (d, $\mathrm{CHO}$ ), $104.43\left(\mathrm{~s}, \mathrm{CHO}_{2}\right), 132.03(\mathrm{~s}, \mathrm{C}=\mathrm{S}), 168.54(\mathrm{C}=\mathrm{O}) . \mathrm{MS}(\mathrm{ESI}$, $\mathrm{m} / z) 785(\mathrm{M}+\mathrm{H})^{+}$.

2-[2-(4-\{4,5-Bis-[3-(2,3-dihydroxypropyl)thioureidomethyl][1,3]-dioxolan-2-ylmethoxy\}ethoxy)ethoxy]-N,N-ditetradecyl- 
Scheme 1. (i) TsCl, Pyridine, $\mathrm{CH}_{2} \mathrm{Cl}_{2},-20{ }^{\circ} \mathrm{C}, 52 \%$; (ii) APTS, 3, Benzene, Reflux, 75\%; (iii) $\mathrm{NaN}_{3}, \mathrm{DMF}$, Reflux, $94 \%$; (iv) NaOH, $\mathrm{MeOH} / \mathrm{H}_{2} \mathrm{O} / \mathrm{THF}$, RT, 97\%; (v) Isobutyl Chloroformate, $\mathrm{N}$-Methylmorpholin, Ditetradecylamine, THF, $-40{ }^{\circ} \mathrm{C}, 46 \%$; $(\mathrm{vi}) \mathrm{Pd} / \mathrm{C}$, $\mathrm{H}_{2}$, Ethanol, RT, 96\%; (vii) $\mathrm{CS}_{2}$, TsCl, DIPEA, $\mathrm{CH}_{2} \mathrm{Cl}_{2}$, RT, 66\%; (viii) Ethanolamine, THF, RT, 39\%; (ix) 3-Aminopropane-1,2-diol, DMF, RT, 38\%
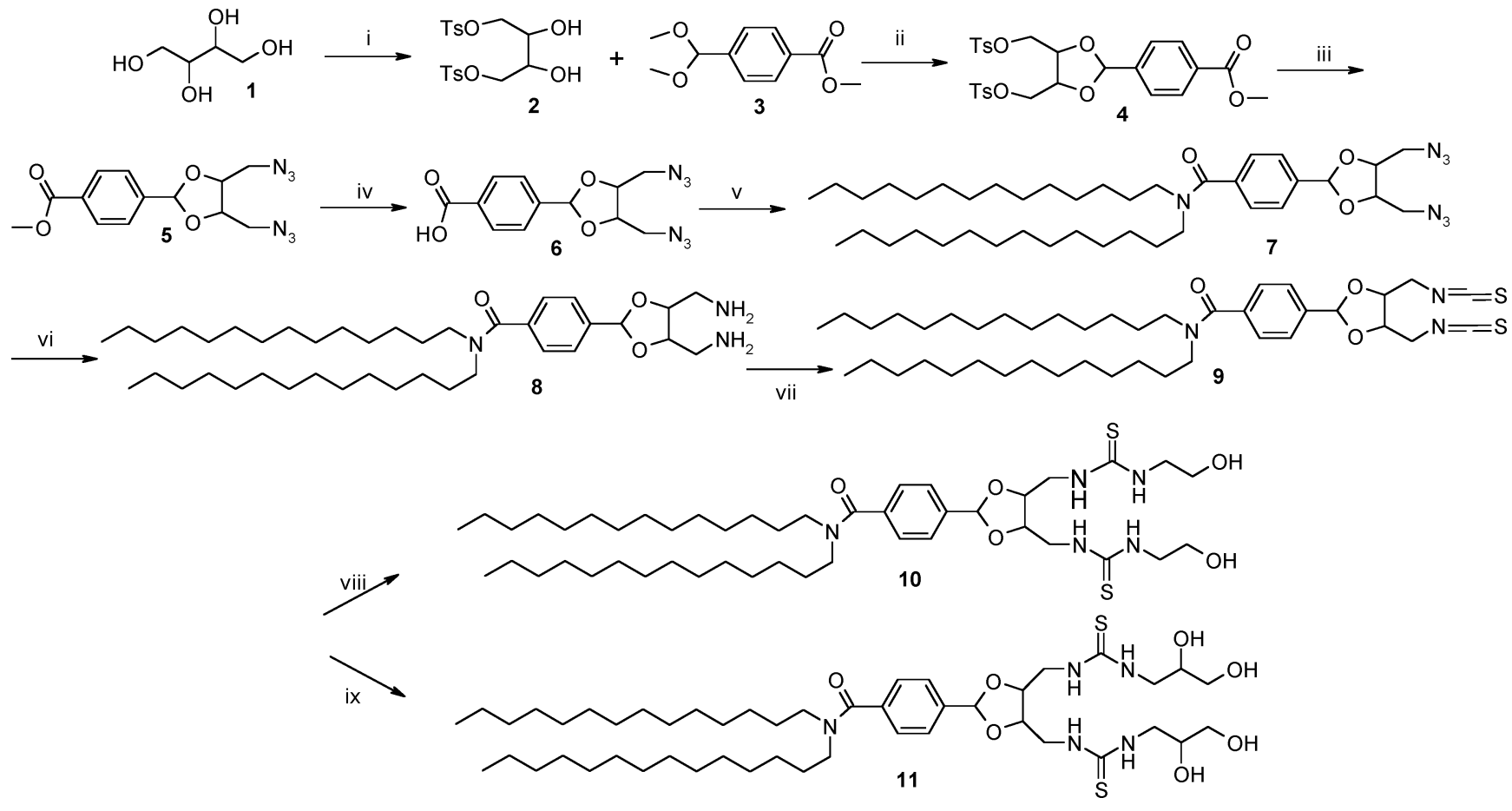

acetamide (20). 3-Amino-1,2-propanediol (0.008 g, $0.092 \mathrm{mmol})$ in DMF $(0.1 \mathrm{~mL})$ was added to a solution of $\mathbf{1 9}(41 \mathrm{mg}, 0.056$ mmol) in dry DMF $(0.2 \mathrm{~mL})$. The solution was stirred at RT for $20 \mathrm{~h}$, then concentrated to dryness. The crude was dissolved in ethyl acetate and washed three times with brine. The organic layer was dried $\left(\mathrm{MgSO}_{4}\right)$ and evaporated to dryness. SFC purification yield 20 as a colorless oil $(0.016 \mathrm{~g}, 72 \%) .{ }^{1} \mathrm{H}$ NMR $\left(\mathrm{CDCl}_{3}\right) \delta(\mathrm{ppm}) 0.88\left(\mathrm{t}, 6 \mathrm{H}, J=6.6 \mathrm{~Hz}, \mathrm{CH}_{3}\right), 1.22-1.29(\mathrm{~m}$, $\left.44 \mathrm{H},-\mathrm{CH}_{2}-\right), 1.52\left(\mathrm{~m}, 4 \mathrm{H},-\mathrm{CH}_{2}-\right), 3.11$ and $3.28(\mathrm{t}, 4 \mathrm{H}$, $\left.J=7.5 \mathrm{~Hz},-\mathrm{CH}_{2} \mathrm{~N}\right), 3.50-3.75\left(\mathrm{~m}, 22 \mathrm{H},-\mathrm{CH}_{2} \mathrm{O}-\right.$, $\left.-\mathrm{CH}_{2} \mathrm{NCS}, \mathrm{CH}_{2} \mathrm{OH}\right), 4.13-4.34\left(\mathrm{~m}, 6 \mathrm{H},-\mathrm{CH}_{2} \mathrm{CO}, \mathrm{CHO}\right.$, $\mathrm{CHOH}), 5.25\left(\mathrm{t}, 1 \mathrm{H}, J=3.6 \mathrm{~Hz}, \mathrm{CHO}_{2}\right) .{ }^{13} \mathrm{C} \mathrm{NMR}\left(\mathrm{CDCl}_{3}\right) \delta$ (ppm) $14.13\left(\mathrm{~s}, \mathrm{CH}_{3}\right), 22.72\left(\mathrm{~s},-\mathrm{CH}_{2}-\right), 27.16\left(\mathrm{~s},-\mathrm{CH}_{2}-\right)$, $28.94\left(\mathrm{~s},-\mathrm{CH}_{2}-\right), 29.67\left(\mathrm{~m},-\mathrm{CH}_{2}-\right), 31.98\left(\mathrm{~s},-\mathrm{CH}_{2}-\right)$, $45.44\left(\mathrm{~s},-\mathrm{CH}_{2} \mathrm{NCS}\right), 46.48$ and $47.14\left(\mathrm{~s},-\mathrm{CH}_{2} \mathrm{NCO}\right), 63.74$ (s, $\left.\mathrm{CH}_{2} \mathrm{OH}\right), 68.98$ (s, $\left.\mathrm{CHOH}\right), 69.84$ (s, $\left.-\mathrm{CH}_{2} \mathrm{O}-\right), 70.28$ (m, $-\mathrm{CH}_{2} \mathrm{O}-$ ), 70.59 (s, $-\mathrm{CH}_{2} \mathrm{CO}$ ), 71.39 (s, $-\mathrm{CH}_{2} \mathrm{O}-$ ), 78.35 (d, CHO), $101.93\left(\mathrm{~s}, \mathrm{CHO}_{2}\right), 169.06(\mathrm{~s}, \mathrm{C}=\mathrm{O}), 183.55$ (s, $\mathrm{C}=\mathrm{S}$ ). ES-HRMS Calcd for $\mathrm{C}_{48} \mathrm{H}_{95} \mathrm{~N}_{5} \mathrm{O}_{10} \mathrm{NaS}_{2}$ : 988.6418 . Found: 988.6389.

Lipopolythiourea Formulation. ARTUtetraol (2.27 mg, 2.5 $\mu \mathrm{mol})$ and DPPC $(3.66 \mathrm{mg}, 5.0 \mu \mathrm{mol})$ were dissolved in a chloroform/acetone/ethanol mixture $(1 / 5 / 4 \mathrm{v} / \mathrm{v} / \mathrm{v}, 500 \mu \mathrm{L})$. This mixture was then added dropwise to $5 \mathrm{~mL}$ of stirred $\mathrm{H}_{2} \mathrm{O}$ and vigorously stirred overnight. Most of the solvents were removed under vacuum to obtain a fairly concentrated suspension of liposomes (concentration of ARTUdiol $=8.5 \mathrm{mM}$ ). Similar procedures were used for the other LPT.

Complex Size. The complex diameter was determined by dynamic light scattering on a Zetasizer Nano Series Malvern. $10 \mu \mathrm{L}$ of ARTUdiol/DPPC $1 / 2(C=8.5 \mathrm{mM})$ was added to $800 \mu \mathrm{L}$ of $\mathrm{H}_{2} \mathrm{O}$; mean value of three runs is given (1 min equilibration, 3 min run).

Preparation of the Complexes LPT/DPPC/DNA. Plasmid DNA (pVax2luc) $\left(100 \mu \mathrm{L}, 0.02 \mathrm{~g} / \mathrm{L}\right.$ in $\left.\mathrm{H}_{2} \mathrm{O}\right)$ was added dropwise with constant vortexing to various amounts of ARTUdiol/DPPC 1/2 particles (for a ratio value of thiourea function over DNA phosphate of 20: $100 \mu \mathrm{L}, 1.2 \mathrm{mM}$ ) at RT.
The samples were left to incubate at RT overnight before size measurements, which were performed on a Zetasizer Nano Series Malvern.

Agarose Gel Electrophoresis. Samples were prepared as described above $(20 \mu \mathrm{L})$, and $5 \mu \mathrm{L}$ of bromophenol blue was added. The mixtures were loaded into $0.8 \%$ agarose gel in TBE buffer (1 M Tris, 0.9 M boric acid, 0.01 M EDTA) at $80 \mathrm{~V} / \mathrm{cm}$. DNA was revealed with ethidium bromide and visualized under UV light.

Luciferase Measurement. The NIH3T3, mice fibroblasts cells, were grown in DMEM medium, supplemented with $10 \%$ fetal bovine serum, $1 \%$ antibiotics (penicillin and streptomycin), and $1 \%$ glutamine. HUVEC cells, primocultures of human unbilical vein endothelial cels, were grown into endothelial cell growth medium kit (Promo Cell) medium. One day before transfection, the cells were treated with trypsin, deposed into 24-well plates (3T3, 50000 cells/well; HUVEC, 70000 cells/ well) and incubated $24 \mathrm{~h}$ at $37{ }^{\circ} \mathrm{C}$. A volume of $200 \mu \mathrm{L}$ of LPT/DNA (corresponding to $0.5 \mu \mathrm{g}$ DNA) complexes was loaded on each well, and the plates are incubated at $37{ }^{\circ} \mathrm{C}$ for $48 \mathrm{~h}$. Then, the cells were washed twice with PBS and lysed with $200 \mu \mathrm{L}$ of a passive lysis buffer (Promega) containing SDS $(2.5 \%)$ and TRIS $(50 \mathrm{mM})$ at $\mathrm{pH} 7.5$. After $15 \mathrm{~min}$, the cells were centrifuged for $5 \mathrm{~min}$ at $12000 \mathrm{rpm}$. $10 \mu \mathrm{L}$ of supernatant and $10 \mu \mathrm{L}$ iodoacetamide were deposited onto a 96-well plate, which was incubated at $37^{\circ} \mathrm{C}$ for $1 \mathrm{~h}$. Protein quantification was performed with the BCA protein assay kit (Pierce) and reported to the BSA taken as a reference curve. Luciferase activity was quantified using a commercial kit Luciferase assay system (Promega). On $10 \mu \mathrm{L}$ of the lysed cells, $50 \mu \mathrm{L}$ of the luciferin substrate was injected via an injector, and the absorbance was read immediately at $563 \mathrm{~nm}$ on a Wallac Victor2 1420 Multilabel Counter (Perkin-Elmer).

RGD-Mediated Lipopolythiourea Liposomes Delivery to HUVEC and NIH3T3 Fibroblast Cells. One day before transfection, HUVEC or NIH3T3 cells were deposed into 12well plates with glass lamellae (3T3, 70000 cells/well; HUVEC, 150000 cells/well) and incubated at $37{ }^{\circ} \mathrm{C}$ for $24 \mathrm{~h}$ in MEM 
Scheme 2. (i) NaH, Bromoacetaldehyde Diethyl Acetal, THF, $60{ }^{\circ} \mathrm{C}, 100 \%$; (ii) APTS, 2, Benzene, Reflux; (iii) APTS, Methanol, RT, 52\% Two Steps; (iv) TEMPO, Trichloroisocyanuric Acid, NaBr, Acetone, RT, 71\%; (v) Isobutyl Chloroformate, $N$-Methylmorpholin, Ditretradecylamine, THF, $-40{ }^{\circ} \mathrm{C}, 42 \%$; (vi) $\mathrm{NaN}_{3}$, DMF, Reflux, 100\%; (vii) $\mathrm{H}_{2}, \mathrm{Pd} / \mathrm{C}$, Ethanol, RT, 100\%; (viii) CS 2 , TsCl, DIPEA, $\mathrm{CH}_{2} \mathrm{Cl}_{2}$, RT, 35\%; (ix) 3-Amino-1,2-propanediol, DMF, RT, 72\%
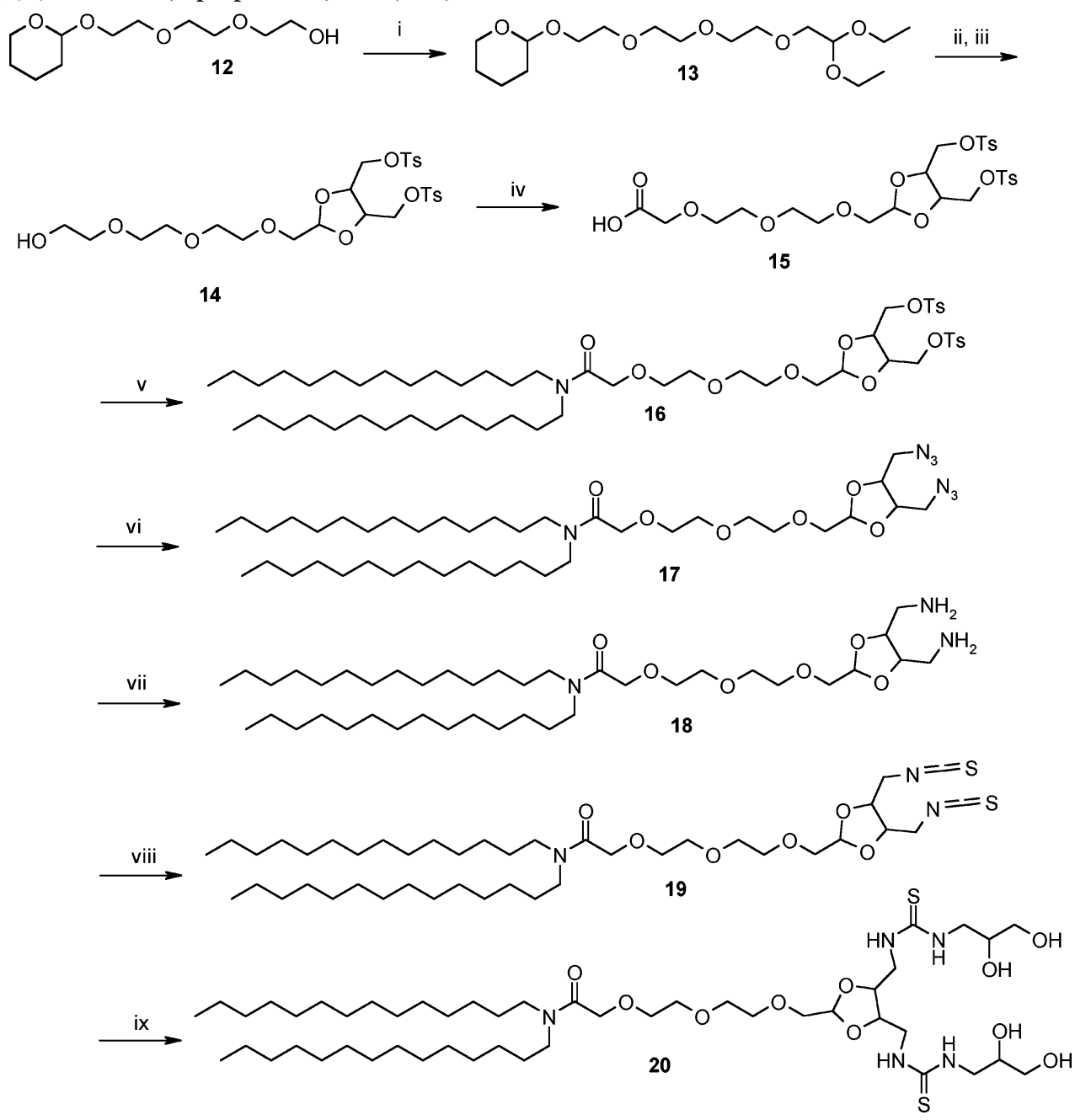

Table 1. Size (nm) of LPT/Colipid Particles Measured in $\mathrm{H}_{2} \mathrm{O}$ on a Malvern Instrument Zetasizer NanoSeries

\begin{tabular}{|c|c|c|c|}
\hline formulation & ARTUdiol & ARTUtetraol & $\mathrm{PEG}_{3}$ TUtetraol \\
\hline DT & no 1 & 79 & \\
\hline LPT/ & $107 \pm$ & $122 \pm 28$ & $142 \pm 49$ \\
\hline LPT/Chol-PEG $45(10: 1)$ & 264 & 130 & ND \\
\hline
\end{tabular}

medium. Lipopolythiourea/DNA complexes $(200 \mu \mathrm{L}, 0.5 \mu \mathrm{g}$ DNA) were loaded in each well. After $7 \mathrm{~h}$ at $37^{\circ} \mathrm{C}$, the wells were washed twice with PBS, and $500 \mu \mathrm{L}$ of PFA (3\% in PBS) was added. The plates were left $30 \mathrm{~min}$ in the dark at RT before being washed twice with PBS. DAPI $(0.05 \mu \mathrm{g}$ in $500 \mu \mathrm{L}$ PBS $)$ was then added. The plates were left $30 \mathrm{~min}$ in the dark, washed with PBS, and treated with mowiol. Fluorescence was observed on a ZEISS Axiophot noninversed microscope.

\section{RESULTS}

Synthesis. Three myristyl compounds were chosen as models to evaluate the impact of LPT structural modifications to DNA compaction and to transfection efficacy. First, the synthesis of compounds $\mathbf{1 0}$ and $\mathbf{1 1}$, bearing an aromatic linker, is described in Scheme 1.

Considering the structure of $\mathbf{1 0}$ and $\mathbf{1 1}$, we chose to investigate a strategy starting from the readily available D,L-threitol (1). Tosylation of $\mathbf{1}$ with two tosyl chloride equivalents proceeded selectively (6:1) to give $\mathbf{2}$ in $52 \%$ yield with the tritosyl derivative as a minor product $(8 \%)(20)$. Attempts to increase the selectivity using the more bulky trisyl chloride provided no improvement (21). Transacetalation with methyl 4-(dihydroxymethyl)cyclohexa-1,3-diene-1-carboxylate 3 (22) in the presence of a catalytic amount of APTS and using a Dean-Stark trap afforded the five-membered-ring acetal $\mathbf{4}$ in $75 \%$ yield (23). Azidation of $\mathbf{4}$ afforded the diazide $\mathbf{5}$ (94\%), then saponification of the methyl ester gave the carboxylic acid 6 (97\%).

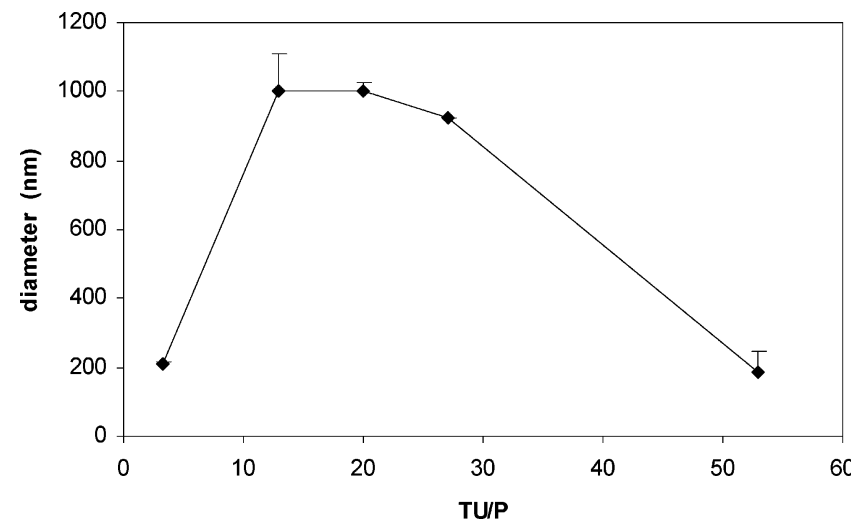

Figure 2. Diameter of particles $\mathrm{PEG}_{3} \mathrm{TUtetraol} / \mathrm{DPPC}$ (1:2) with increasing amounts of DNA measured in $\mathrm{H}_{2} \mathrm{O}$ on a Malvern Instrument Zetasizer NanoSeries (ratio TU/P $=$ mol thiourea functions $/$ mol DNA phosphate groups). 

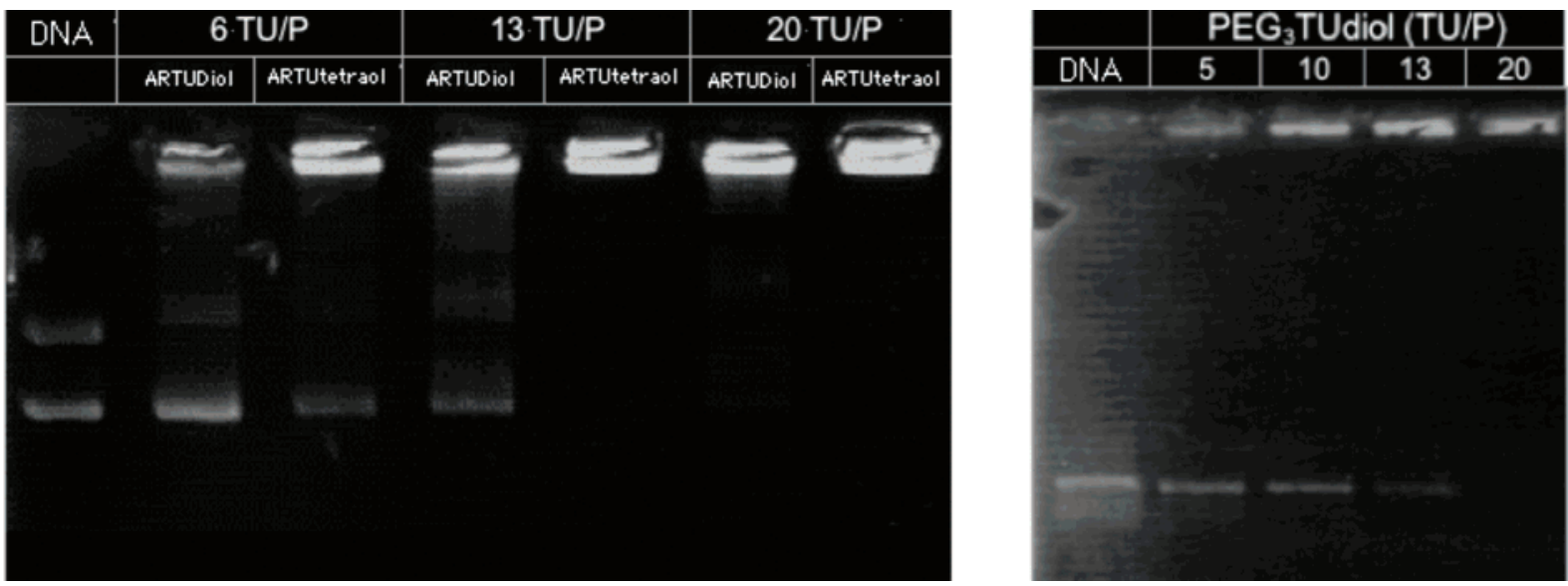

Figure 3. Migration of the ARTUdiol/DPPC(1:2)/DNA and ARTUtetraol/DPPC(1:2)/DNA complexes (left) and PEG 3 TUtetraol/DPPC(1:2)/DNA complexes (right) on a $0.8 \%$ agarose gel in TBE $(1 \times)$. DNA was revealed with ethidium bromide and visualized under UV light.
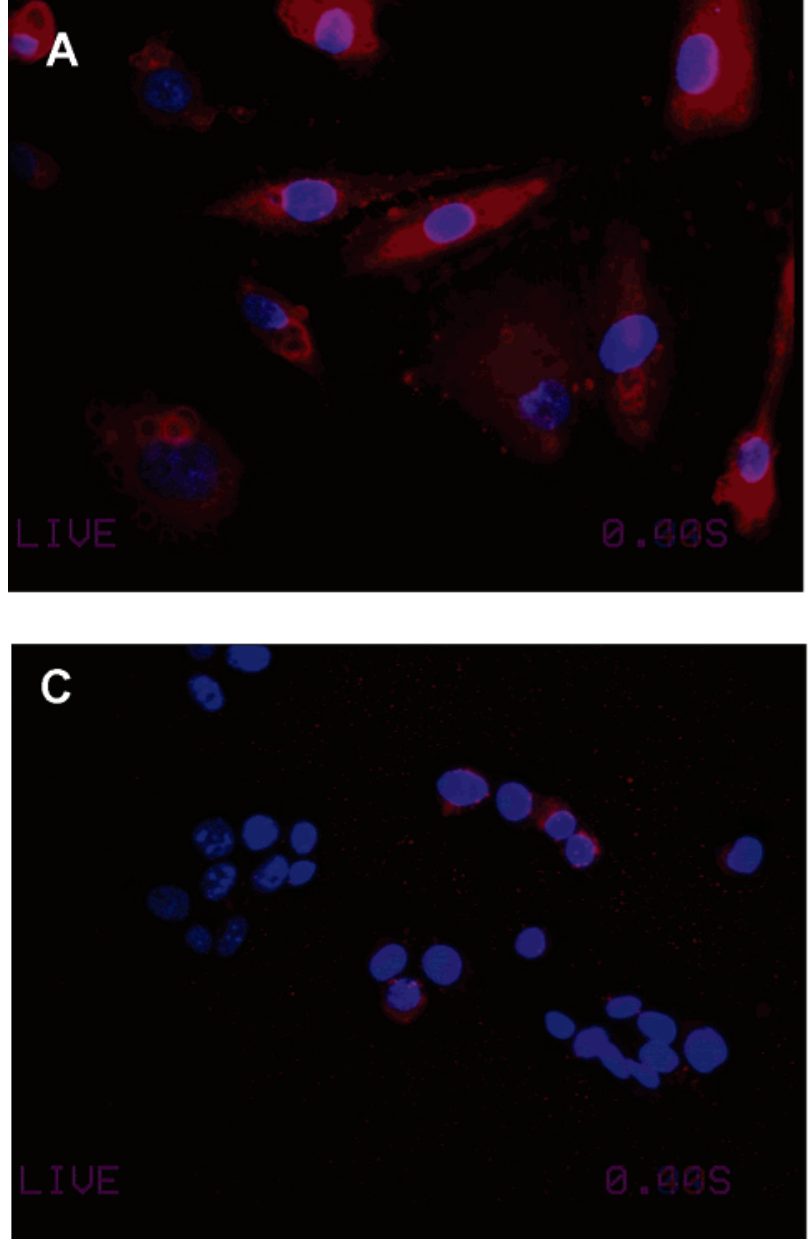
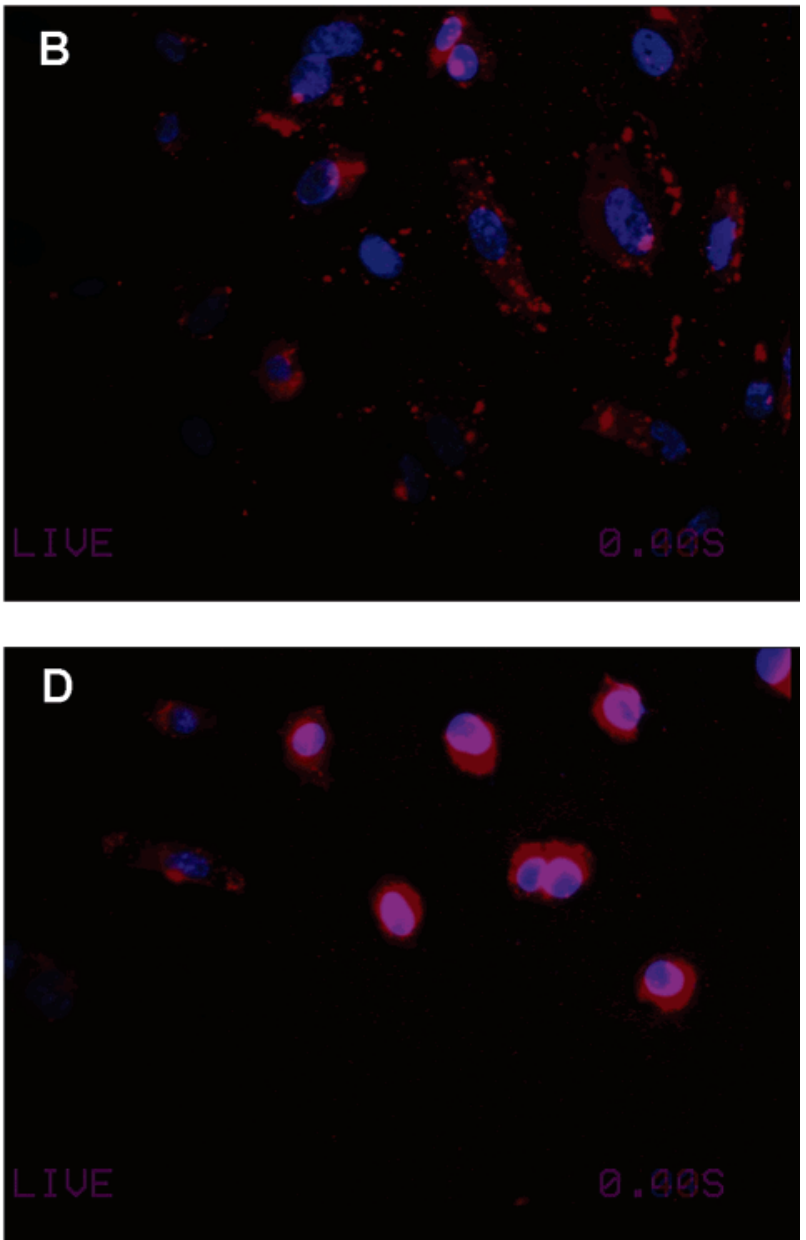

Figure 4. Fluorescence microscopy of ARTUtetraol particles. ARTUtetraol/DPPC/ CholPEG $45 / \mathrm{DOPE}^{-\mathrm{Rhodamine}}(10: 10: 0.20: 0.1) \pm \mathrm{Chol}-$ $\mathrm{PEG}_{75}-\mathrm{RGD}-4 \mathrm{C}(0.2)$ complexes were incubated for $7 \mathrm{~h}$ on HUVEC cells (A and $\mathrm{B}$ ) in the absence (A) or presence (B) of RGD ligand, and on NIH3T3 cells (C and D) in the absence (C) or presence (D) of RGD ligand. Nuclei are stained with DAPI .

Subjecting 6 to amidation with ditetracedylamine using a mixed-anhydride procedure (24) provided good access to compound 7. Catalytic reduction of the diazide 7 effected the conversion to the diamine $\mathbf{8}$ in high yield. The bis-isothiocyanate $\mathbf{9}$ was obtained in good yield by the reaction of $\mathbf{8}$ with $\mathrm{CS}_{2}$ in the presence of tosyl chloride (25). The desired lipopolythioureas 10 and 11 were ultimately prepared by condensation of 9 with ethanolamine and 3-aminopropane-1,2-diol, respectively.

The synthesis of the lipopolythiourea bearing a short PEG linker is described in Scheme 2. It started with the synthesis of 2-\{2-[2-(tetrahydropyranyl-2-yloxy)ethoxy]ethoxy\}ethanol (12) as described in the literature (26).

Then, substitution of the hydroxyl terminus with bromoacetaldehyde diethyl acetal (27) led to the diethoxy acetal 13 that was converted to the 1,3-dioxolane $\mathbf{1 4}$ through treatment with diol 2 in the presence of APTS. Oxidation of 14 was performed using TEMPO and trichloroisocyanuric acid (28). The resulting acid $\mathbf{1 5}$ was treated with isobutyl chloroformate and ditetradecylamine to afford the amide 16. Substitution of the tosyl group of $\mathbf{1 6}$ with sodium azide followed by palladium 
reduction of the azido group gave the diamine $\mathbf{1 8}$ quantitatively. Elaboration of the diisothiocyanate $\mathbf{1 9}$ from the diamine $\mathbf{1 8}$ proved to be difficult and led to a modest $35 \%$ yield. Addition of 3-amino-1,2-propanediol to $\mathbf{1 9}$ completed the synthesis of the lipopolythiourea 20.

Formulation Study. Compounds 10 (ARTUdiol) and 11 (ARTUtetraol) bear the same aromatic linker and differ only by the number of hydroxyl groups attached to the thiourea functionalities. Compound $\mathbf{2 0}$ is similar to compound $\mathbf{1 1}$ ( $\mathrm{PEG}_{3} \mathrm{TUtetraol}$ ) considering the thiourea part, but differs by its linker. In terms of the hydrophilic/hydrophobic balance, we expected ARTUdiol < ARTUtetraol < PEG $_{3}$ tetraol.

The ability of these 3 LPTs to form micellar or liposomal particles was evaluated. Similarly to the previously studied linear LPT (13), we chose DPPC or PEG 45 lipid as co-lipids because of the hydrophobic behavior of the LPT. Several formulations were evaluated (Table 1). ARTUdiol/DPPC (1:2), ARTUtetraol/DPPC (1:1 and 1:2), ARTUdiol/Chol-PEG 45 (10:1), ARTUtetraol/Chol-PEG 45 (10:1), and PEG 3 TUtetraol/ DPPC (1:2) led to small particles whose diameters ranged from 100 to $250 \mathrm{~nm}$, depending on the co-lipid. It is noteworthy that only ARTUtetraol could be formulated with 1 equiv of DPPC. Comparison among the aromatic lipids indicated that a tetraol terminus eased the formulation, since ARTUtetraol required a lower amount of DPPC than ARTUdiol, with the tetraol moiety probably increasing the hydrophilicity. Comparison of the two tetraol lipids showed that the lipid bearing an aromatic linker had a better capacity to form particles, possibly due to aromatic $\pi-\pi$ stacking within the lipid bilayer (29).

Interaction of LPT/DPPC with DNA. The capacity of LPT/ DPPC (1:2) particles to associate to plasmid DNA was then studied. Setting a fixed DNA amount, we added on the DNA solution an increasing amount of lipids. After one night of incubation, we measured the size of the complexes by dynamic light scattering. The results are reported for $\mathrm{PEG}_{3}$ TUtetraol (Figure 2), but similar data have been obtained for ARTUdiol and ARTUtetraol. In the presence of DNA, we observed a size increase from $200 \mathrm{~nm}$ to the micrometer range, proving an interaction between lipopolythiourea particles and plasmid DNA. Adding an excess of lipids (30 equiv thiourea functions/DNA phosphate groups) let the system return to a colloidal stability.

Gel retardation experiments of LPT/DPPC/DNA complexes were performed to evaluate DNA association to particles ARTUdiol/DPPC (1:2), ARTUtetraol/DPPC (1:2), and PEGTUtetraol/DPPC (1:2). Partial retardation was observed above 6 thiourea functions/DNA phosphate groups (TU/P), and complete retardation was observed for ratios of $13 \mathrm{TU} / \mathrm{P}$ for ARTUtetraol and 20 TU/P for ARTUdiol and PEG $_{3}$ TUtetraol (Figure 3). In our previous study (13), complete retardation was obtained for a ratio equal to 20 thiourea functions/DNA phosphate groups (TU/P). Thus, we observed that, using branched lipids bearing only two thiourea functions, we could obtain an interaction with DNA at lower or identical ratio TU/P, as compared to the DTTU lipid bearing three linear functions. These data indicated that a stable interaction between LPT and DNA could be established with only two thiourea groups.

Transfection Activity and RGD-Mediated Delivery into Endothelial Cells. DNA transfection mediated by ARTUdiol, ARTUtetraol, and PEGTUtetraol led to disappointing results, since no significative luciferase activity could be measured on the treated B16 cell. This lack of transfection activity may be explained by the noncationic nature of the LPT, causing poor contact with cell membranes. To improve these interactions, RGD-mediated internalization of endothelial cells expressing integrin $\alpha_{\mathrm{V}} \beta_{3}$ was investigated. Thus, we added a PEG 75 -lipid bearing a RGD peptide (14) to the formulation, and a rhodaminelabeled lipid/DNA complex were prepared. Their intracellular fate was investigated using fluorescence microscopy. These experiments were carried out on two cell types: human umbilical vein endothelial cells (HUVEC), which express integrin $\alpha_{\mathrm{V}} \beta_{3}$, and NIH3T3 fibroblasts, taken as a negative control. Only the results with ARTUtetraol are shown in Figure 4. In the absence of Chol-PEG-RGD, we only observed extracellular binding of lipoplexes to the cell membrane. Such a result has also been reported for PEGylated lipoplexes (30). However, in its presence, we clearly saw intracellular punctuations, which indicated particle internalization. In opposition, no internalization was observed in NIH3T3 cell fibroblasts, although the extracellular binding to cell membranes seemed to be stronger with the RGD group. Thus, addition of Chol-PEG-RGD allowed a specific uptake of the LPT/DNA complexes into the cells. These results are in agreement with the specific capture previously reported on RGD-functionalized spherulites (31). However, this has been found to lead to neither HUVEC nor NIH3T3 transfection. This might result from a lack of DNA release from the LPT/DNA complex, possibly due to the PEGlipid, that was shown to stabilize lipoplexes and reduce transfection efficiency (32).

\section{CONCLUSION}

These results present new lipopolythioureas able to associate DNA. Adding a diol or a tetraol terminus to the thiourea part improved the hydrophilicity and eased the DNA formulation. Use of Chol-PEG-RGD allowed observation of a specific internalization of the complexes in HUVEC cells as shown earlier with other particle types, such as spherulite. On the other hand, these particles were unable to transfect DNA, an effect which might be related to the presence of a PEG moiety in the formulation, thus inducing a shielding effect, which has been shown to affect transfection. Work is in progress to obtain more hydrophilic thiourea compounds and to study the internalization using an RGD derivative without any PEG moiety.

\section{ACKNOWLEDGMENT}

This work was financially supported by INSERM, CNRS, MNERT, and the Région Ile de France (SESAME, CPER). JL thanks the MNERT for a doctoral fellowship.

\section{LITERATURE CITED}

(1) Ruponen, M., Honkaski, P., Rönkkö, S., Tammi, M., and Urtti, A. (2003) Extracellular and intracellular barriers in non-viral gene delivery. J. Controlled Release 93, 213-217.

(2) Wells, D. J. (2004) Gene therapy progress and prospects: electroporation and other physical methods. Gene Ther. 11, 1363-136.

(3) Verma, I. M., and Weitzman, M. D. (2005) Gene therapy: twentyfirst century medicine. Annu. Rev. Biochem. 74, 711-738.

(4) Thomas, A. E., Ehrhardt, A., and Kay, M. A. (2003) Progress and problems with the use of viral vectors for gene therapy. Nat. Rev. Genet. 4, 346-358.

(5) Nicolazzi, C., Garinot, M., Mignet, N., Scherman, D., and Bessodes, M. (2003) Cationic lipids for transfection. Curr. Med. Chem. 10, $1263-1277$

(6) Pack, D. W., Hoffman, A. S., Pun, S., and Stayton, P. S. (2005) Design and development of polymers for gene delivery. Nat. Rev. Drug Discovery 4, 581-593.

(7) Dass, C. R. (2004) Lipoplex-mediated delivery of nucleic acids: factors affecting in vivo transfection. J. Mol. Med. 82, 579-591.

(8) Nicolazzi, C., Mignet, N., de la Figuera, N., Cadet, M., Ibad, R. T., Seguin, J., Scherman, D., and Bessodes, M. (2003) Anionic polyethyleneglycol lipids added to cationic lipoplexes increase their plasmatic circulation time. J. Controlled Release 88, 429-43.

(9) Arigon, J., Prata, C. A. H., Grinstaff, M. W., and Barthélémy, P. (2005) Nucleic acid complexing glycosyl nucleoside-based amphiphile. Bioconjugate Chem. 16, 864-872.

(10) Thompson, B., Mignet, N., Hofland, H., Lamons, D., Seguin, J., Nicolazzi, C., de la Figuera, N., Kuen, R. L., Meng, X. Y., Scherman, 
D., and Bessodes, M. (2005) Neutral postgrafted colloidal particles for gene delivery. Bioconjugate Chem. 16, 608-614.

(11) Takemoto, Y. (2005) Recognition and activation by ureas and thioureas: stereoselective reactions using ureas and thioureas as hydrogen-bonding donors. Org. Biomol. Chem. 3, 4299-4306.

(12) Buhlmann, P., Nishizawa, S., Xiao, K. P., and Umezawa, Y. (1997) Strong hydrogen bond-mediated complexation of $\mathrm{H}_{2} \mathrm{PO}_{4}{ }^{-}$by neutral bis-thiourea hosts. Tetrahedron 53, 1647-1654.

(13) Tranchant, I., Mignet, N., Crozat, E., Leblond, J., Girard, C., Scherman, D., and Herscovici, J. (2004) DNA complexing lipopolythiourea. Bioconjugate Chem. 15, 1342-1348.

(14) Tranchant, I., Thompson, B., Nicolazzi, C., Mignet, N., and Scherman, D. (2004) Physicochemical optimisation of plasmid delivery by cationic lipids. J. Gene Med. 6, Suppl. 1, S24-S35.

(15) Petit, L., Joubert, L., Tranchant, I., Herscovici, J., and Adamo, C. submitted.

(16) Byk, G., Dubertret, C., Escriou, V., Jaslin, G., Rangara, R., Pitard, B., Crouzet, J., Wils, P., Schwartz, B., and Scherman, D. (1998) Synthesis, activity and structure-activity relationship studies of novel cationic lipids for DNA transfer. J. Med. Chem. 41, 224-235.

(17) Majeti, B. K., Karmali, P. P., Reddy, B. S., and Chaudhuri, A. (2005) In vitro gene transfer efficacies of $N, N$-dialkylpyrrolidinium chlorides: a structure-activity investigation. J. Med. Chem. 48, 3784-3795.

(18) Still, W. C., Kahn, M. and Mitra, A. (1978) Rapid chromatographic technique for preparative separations with moderate resolution $J$. Org. Chem. 43, 2923-2926.

(19) Balacco, G. (1994) SwaN-MR: A Complete and Expansible NMR Software for the Macintosh. J. Chem. Inf. Comput. Sci. 34, 1235124.

(20) Sommerdijk, N. A., Hoeks, T. H., Synak, M., Feiters, M. C., Nolte, R. J., and Zwanenborg, B. (1997) Stereodependent fusion of vesicles: calcium binding of synthetic gemini phospholipids containing two phosphate groups. J. Am. Chem. Soc. 119, 4338-4344.

(21) White, J. D., Bolton, G. L., Dantanarayana, A. P., Fox, C. M., Hiner, R. N., Jackson, R. W., Sakuma, K., and Warrier, U. S. (1995) Total synthesis of the antiparastic agent avermectin B1a. J. Am. Chem. Soc. 117, 1908-1939.

(22) Methyl 4-(dihydroxymethyl)cyclohexa-1,3-diene-1-carboxylate 3 was prepared in one step by the reaction of 4-formylcyclohexa-1, 3-diene-1-carboxylic acid with thionyl chloride in methanol.
(23) Harada, T., Nakamura, T., Kinusaga, M., and Oku, A. (1999) Mechanism of chiral Lewis acid mediated enantiotopic groupselective ring cleavage of cyclic acetals derived from meso-1,2-diols. J. Org. Chem. 64, 7594-7600.

(24) Wender, P. A., Jessop, T. C., Pattabiraman, K., Pelkey, E. T., and VanDeusen, C. L. (2001) Efficient, scalable synthesis of the novel molecular transporter Octa-Arginine. Org. Lett. 3, 3229-3232.

(25) Stephensen, H., and Zaragoza, F. (1997) Resin-bound isothiocyanates and their synthetic equivalents as intermediates for the solidphase synthesis of substituted thiophenes. J. Org. Chem. 62, 60966097.

(26) Loiseau, F., Hii, K., and Hill, A. (2004) Multigram synthesis of well-defined extended bifunctional polyethylene glycol (PEG) chains. J. Org. Chem. 69, 639-647.

(27) Keane, J. F., Cuomo, J., Lex, L., and Seyedrezai, S. E. (1983) Azoethoxy nitroxide spin-labeled crown ethers and cryptands with the N-O group positioned near the cavity. J. Org. Chem. 48, 26472654.

(28) De Luca, L., Giacomelli, G., Masala, S., and Porcheddu, A. (2001) A very mild and chemoselective oxidation of alcohols to carbonyl compound. Org. Lett. 3, 3041-3043.

(29) Bhattacharya, S., Subramanian, M., and Hiremath, U. S. (1995) Surfactant lipids containing aromatic units produce vesicular membranes with high thermal stability. Chem. Phys. Lipids 78, 177188.

(30) Shi, F., Wasingu, L., Nomoden, A., Stuart, M. C., Polushkin, E., Engberts, J. B., and Hoekstra, D. (2002) Interference of poly(ethylene glycol)-lipid analogues with cationic-lipid-mediated delivery of nucleotides; role of lipid exchangeability and non-lamellar transitions, Biochem. J. 366, 333-341.

(31) Chenevier, P., Delord, B., Amedee, J., Bareille, R., Ichas, F., and Roux, D. (2002) RGD-functionalized spherulites as targeted vectors captured by adherent cultured cells. Biochim. Biophys. Acta 1593, 17-27.

(32) Song, L. Y., Ahkong, Q. F., Rong, Q., Wang, Z., Ansell, S., Hope, M. J., and Mui, B. (2002) Characterization of the inhibitory effect of PEG-lipid conjugates on intracellular delivery of plasmid and antisense DNA mediated by cationic liposomes. Biochim. Biophys. Acta 1558, 1-13.

BC060110G 